Review of
ECONOMICS
and
INSTITUTIONS

\title{
Pro-Poor Progress in Education in Developing Countries?
}

\author{
Kenneth Harttgen ${ }^{\varpi}$ \\ University of Göttingen
}

\author{
Stephan Klasen \\ University of Göttingen
}

\author{
Mark Misselhorn \\ University of Göttingen
}

\begin{abstract}
Attendance in education and associated years of schooling have expanded substantially in developing countries in recent years. But has this expansion in enrolments reduced existing inequalities in educational access and achievements? This paper analyzes differences in improvements in the access to the education system and in educational outcomes across the welfare distribution between and within countries, and also by gender and regions for a sample of 37 developing countries using Demographic and Health Surveys (DHS). For the analysis, the toolbox of pro-poor growth analysis is applied to several educational indicators. We find drastic inequalities in educational attendance across the income distribution. Interestingly, inequalities in attendance declines with rising average attendance, while inequality in completion rates or schooling years increases with rising completion rates or schooling years.
\end{abstract}

JEL classification: 120, 129, 131, 132

Keywords: education, human capital, inequality, pro-poor growth

\section{Introduction}

Access to high-quality education is an important constituent element of well-being, as suggested, for example, by Sen's capability approach (Sen, 1998). Moreover, it has been found to accelerate economic growth as well as to promote political stability and social cohesion (e.g., Chabott and Ramirez, 2000; LeVine et al., 2004; Milligan et al., 2003). Education also has

We want to thank Michael Grimm, Kevin Watkins, and participants at workshops in Göttingen for helpful comments and discussion. Funding from UNESCO in support of this work is gratefully acknowledged.

$\llbracket$ Corresponding author. Address: University of Göttingen, Platz der Göttinger Sieben 3, 37073 Goettingen, Germany (Phone: +49-551-398175, Fax: +49-551-397302; Email: k.harttgen@wiwi.uni-goettingen.de)

\section{Recommended Citation}

Harttgen, K., Klasen, S., Misselhorn, M. (2010). Pro-Poor Progress in Education in Developing Countries?

Review of Economics and Institutions, 1 (1), Article 6. doi:10.5202/rei.v1i1.6

Retrieved from http://www.rei.unipg.it/rei/article/view/6 
a direct impact on other dimensions of human well-being (i.e., the other Millennium Development Goals - MDGs) such as child health and nutrition (e.g., Duflo and Breierova, 2004; Schultz, 2002). In addition, there also exists a strong relationship between education, poverty and inequality. On the one hand, education reduces poverty and inequality. Sustained economic growth and poverty reduction result in higher levels of household resources allowing higher investments in their children's education because parents are less dependent on their children's labor. On the other hand, existing poverty and inequality may be worsened through poor education. Many researchers have shown that poverty significantly reduces the likelihood of school participation (e.g., Smits et al., 2007).

To enhance access to education, policy-makers can work on supply-side and/or demand-side interventions. Supply-side interventions aim to improve the quantity and quality of schools. Especially the provision of primary and secondary schools is important in areas that show very low levels of attendance. However, school provision becomes less effective in countries where schools already exist in an accessible distance (e.g., Duflo, 2001; Filmer, 2004; Pritchett, 2004). Raising the quality of schooling is a more complex agenda having to do with the training and incentive system of teachers, the structure of the education system, the provision of materials, and the like (e.g., Wößmann, 2003; Pritchett, 2004).

Demand-side interventions aim to influence the preferences of parents for their children's education. Policy interventions here can be targeted directly to the currently less educated population group (Orazem et al., 2008). While improvements in school quality will surely increase demand for education by parents (e.g., De and Dreze, 1999; Pritchett, 2004), three different measures are usually considered to increase demand for education: interventions in health and nutrition, lowering schooling costs, or subsidies or conditional cash transfers tied to education. First interventions in child health and nutrition aim to improve the physical and mental ability to learn (e.g., Glewwe at al., 2001; Miguel and Kremer, 2004; Alderman et al., 2003). The means for this intervention are typically the distribution of nutrient supplements, health interventions at school (e.g., immunization, de-worming), the provisions of school lunches and school based immunization programs. Second, programs to reduce schooling costs can have a direct and relatively quick impact on school attendance rates and years of schooling completed. High schooling costs are still a particular problem for many households in many developing countries (Orazem et al., 2008). In recent years, several countries have dropped school fees in an effort to boost enrolments (e.g., Ghana, Kenya, Tanzania, and Uganda). Third, targeted subsidy programs or conditional cash transfers aim to induce parents to send their children to school. These programs are often accompanied by other components like nutritional 
supplements and health provisions. Countries that have implemented such programs are, for example, Brazil, Mexico, Colombia, Nicaragua, Peru, and Bangladesh. These programs are most effective in regions in which schooling demand is highly income and price elastic and where attendance rates are very low, i.e., it targets the very poor households especially in rural areas. In addition, conditional cash transfers can also be of particular relevance for reducing the gender gap in education (King et al., 2008).

Given the high promise of education and the large gaps in educational access persisting in many developing countries, the World Conference on Education for All in Jomtien, Thailand, adopted in 1990 the World Declaration on Education for All, which stated that everyone has a right to a full cycle of education. Because of insufficient progress in access to education and educational outcomes in the developing world, in Dakar in the year 2000, the World Education Forum adopted a new framework for Action containing six Education for All (EFA) goals to be reached until the year 2015 to overcome the persisting shortcomings in education ${ }^{1}$. In addition, two of the eight Millennium Development Goals (MDGs) committed by the United Nations (UN) in the year 2000 (in particular MDG 2 - achieve universal primary education - and MDG 3 - promote gender equality and empower women) directly emphasize the importance of education for human development. The explicit inclusion of education among the MDGs reflects that these indicators are fundamental dimensions of human well-being.

Today, more than half of the time period to reach the EFA goals and the MDGs has passed. During the last decade, many regions, particular in East and South Asia, have made significant progress towards the achievement of the goals by 2015. The latest EFA Global Monitoring Report (UNESCO, 2008) provides a comprehensive mid-term overview of progress towards the Education for all goals set at Dakar in 2000. While there is great regional heterogeneity, it shows that overall in developing countries, the net attendance rate in primary education has increased from 79 percent in 1991 to 86 percent in 2005. Faster progress has been made between 1999 and 2005 than between 1991 and 1999. For example, participation in primary education increased in Sub-Saharan Africa from 54 percent in 1991 to 57 percent in 1999 and 70 percent in 2005 (UNESCO, 2008).

\footnotetext{
${ }^{1}$ The six EFA goals adopted in the years 2000 to be reached until the years 2015 are: the expansion of early childhood care and education, the achievement of universal primary education, the development of learning opportunities for youth and adults, the spread of literacy, the achievement of gender parity and gender equality in education and improvements in education quality.
} 
These averages hide that many groups within a country have already reached the EFA goals, while others are lagging far behind. Thus overall progress in meeting the EFA goals will depend on reducing existing inequalities in educational access. Wide disparities in progress remain between population subgroups, e.g., between males and females and rich and poor. There also exist significant within country differences in access to education and in educational outcomes especially between urban and rural areas (UNESCO, 2008).

The purpose of this paper is to analyze the distribution of progress in educational access (using secondary attendance and years of completed schooling as our key indicators) over the last 15 years along the welfare distribution for a large sample of developing countries. In particular, we use a common survey instrument, the Demographic and Health Surveys, for 37 developing countries at several points in time to document educational inequalities along the welfare distribution and their change over time. For this analysis, we make use of a toolbox recently developed for pro-poor growth research (Ravallion and Chen, 2003; Klasen, 2008; Grosse et al., 2008) that makes use of growth incidence curves and measures of pro-poor growth to examine whether the poor have disproportionately benefited from expansions in education or not.

The rest of the paper is organized as follows. Section 2 provides a short introduction in the concept of pro-poor growth and how one can introduce this concept to analyze pro-poor educational outcomes. Section 3 describes the methodology of the analysis and Section 4 describes the data used. Section 5 presents the results. Section 6 concludes.

\section{Assessing Pro-Poor Educational Outcomes}

Pro-poor growth is often defined as economic growth that benefits the poor (e.g., UN, 2000; OECD, 2001, 2006). While this concept was initially focused on the income dimension, one can just as easily extend this type of analysis to non-income indicators (Grosse et al., 2008). When discussing pro-poor growth, one can refer to growth rates that are associated with declining poverty (e.g., Ravallion and Chen, 2003), growth rates that are higher for the poor and thus associated with declining relative inequality (e.g., Kakwani and Son, 2008), and absolute improvements that are larger for the poor and thus associated with declining absolute inequality (e.g., Duclos and Wodon, 2004). Klasen (2008) categorized the first as weak absolute, the second as relative, and the third as strong absolute pro-poor growth, respectively ${ }^{2}$. Accordingly, one can also calculate a rate of pro-

\footnotetext{
${ }^{2}$ For a detailed review on the different definitions and measures of pro-poor growth see, for example, Son (2003), Kakwani and Son (2008) or Ravallion and Chen (2003).
} 
poor growth, as suggested by Ravallion and Chen (2003), which summarizes the distribution of progress in one number. This and other methodological questions are discussed in the following section.

\section{Methodology}

\subsection{Distribution of Educational Outcomes}

To separate the population into welfare groups (i.e., percentiles, vintiles and/or quintiles), one typically uses information on income or expenditure. As we do not have information on income or expenditure in our DHS data sets, we consider an alternative approach to define the socio-economic status of a household. In particular, we use an asset-based approach in defining well-being proposed by Filmer and Pritchett (2001) and Sahn and Stifel (2003). Sahn and Stifel (2003) show that such an asset index is an accurate indicator of long-term well-being. The main idea of this approach is to construct an aggregated uni-dimensional index over the range of different dichotomous variables of household assets capturing housing durables and information on the housing quality that indicate the material status (welfare) of the household:

$$
A_{i}=\tilde{\gamma}_{1} a_{i 1}+\ldots+\tilde{\gamma}_{n} a_{i n}
$$

where $A_{i}$ is the asset index, the $a_{i n}$ 's refer to the respective asset of the household $i$ recorded as dichotomous variables in the DHS data sets and $\tilde{\gamma}$ are the respective weights for each asset that are to be estimated.

For the estimation of the weights and for the aggregation of the index, we use a principal component analysis as proposed by Filmer and Pritchett $(2001)^{3}$. In particular, as the components for the asset index we include dichotomous variables on the following asset holdings in a household: radio, TV, refrigerator, bike, motorized transport, capturing household durables; type of floor material, type of wall material, type of toilet, and type drinking water capturing the housing quality. We calculate the asset indices separately for each country and period ${ }^{4}$.

After having derived the aggregated index, one can derive the welfare distribution and classify population welfare subgroups $p$. For example,

\footnotetext{
${ }^{3}$ An alternative way to estimate the weights for the assets to derive the aggregated index is a factor analysis employed, for example, by Sahn and Stifel (2003). However, the two estimation methods show very similar results.

${ }^{4}$ The asset index is calculated for each individual, weighted by the household size. For the analysis in rural and urban areas, we calculate separate asset indices for the two regions.
} 
using quintiles as the segmentation dimension, quintile 1 would correspond to the poorest population subgroup and quintile 5 to richest, respectively. Using this welfare distribution, we analyze the access to the education system and educational outcomes, measured by several indicators that are described below, by welfare groups within countries for several periods and also over time.

\subsection{The Non-Income Growth Incidence Curve}

An often used tool in studying the distributional pattern of income growth is the Growth Incidence Curve (GIC, Ravallion and Chen, 2003), which shows the mean growth rate $g_{t}$ in income $y$ at each percentile $p$ of the distribution between two points in time, $t-1$ and $t$. The GIC links the growth rates of different percentiles and is given by

GIC $: g_{t}(p)=\frac{y_{t}(p)}{y_{t-1}(p)}-1, \forall p=1,2, \ldots, 100$

By comparing the two periods, the GIC plots the population percentiles (from 1-100 ranked by income) on the horizontal axis against the annual per capita growth rate in income of the respective centile. If the GIC is above 0 for all percentiles $\left(g_{t}(p)>0\right.$ for all $\left.p\right)$, then it indicates weak absolute pro-poor growth. If the GIC is negatively sloped it indicates relative pro-poor growth. If the GIC plots absolute improvements (rather than growth rates, see also below) on the Y-axis, then a downward sloping GIC signifies strong absolute pro-poor growth. It is important to note that we assume anonymity throughout, i.e., we consider the growth rates of percentiles, even though they contain different households or individuals in the two periods 5 .

To calculate the non-income growth incidence curves, we follow the approach of Grosse et al. (2008). The calculation of the non-income growth incidence curves (NIGIC) broadly follows the concept of the GIC. Instead of income $(y)$, we apply equation (2) to selected education indicators to measure pro-poor progress in education directly via outcome-based welfare indicators over time.

We calculate the NIGIC sorting individuals by welfare level and calculating, based on this welfare ranking, the population percentiles of the education variables ${ }^{6}$. With this conditional ranking, one can address

${ }^{5}$ For further discussion and results when the anonymity axiom is lifted, see Grimm (2007).

${ }^{6}$ One could also sort households/individuals by initial education indicators. This has been called the unconditional NIGIC in Klasen (2008) and Grosse et al. (2008). See these papers for a discussion of the relevance of conditional versus unconditional NIGICs.

http://www.rei.unipg.it/rei/article/view/6 
the question whether and, if yes, to what extent the poor have benefited disproportionately from improvements in education compared to the rich $^{7}$. This means that the conditional NIGIC provides a tool to investigate how the progress in non-income dimensions of poverty was distributed over the income distribution ${ }^{8}$.

Last we have to define a criterion under which we declare growth (or progress) between two periods in time as pro-poor. Starting from the GIC, Ravallion and Chen (2003) define the pro-poor growth rate (PPGR) as the area under the GIC up to the headcount ratio $\mathrm{H}$, which has a direct relation to poverty reduction if one uses the Watts index as the relevant poverty measure. If the PPGR exceeds the growth rate in mean (GRIM), growth is declared to be pro-poor in the relative sense. In the application below, we use the poorest 40 percent of households as the 'poor' and thus investigate the relationship between educational growth among them, compared to mean educational growth.

As already discussed, an alternative way to consider pro-poor growth is by looking on absolute improvements. Especially when looking at changes in non-income indicators of human wellbeing, absolute improvements provide a more meaningful assessment of whether the poor have been benefited more from progress than the non-poor. For example, comparing two individuals, one with 1 years of education and one with 10 , an increase in education for the education-poor individual of $20 \%$ and the education-rich individual of $10 \%$ suggests high levels of relative pro-poor

\footnotetext{
${ }^{7}$ Whereas the growth incidence curve is calculated based on percentiles $(p=1 ; 2 ; \ldots ; 100)$, in this paper, we calculate the growth rates, both for the conditional and unconditional distribution, based on vintiles $(p=1 ; 2 ; \ldots ; 20)$. The reason for using vintiles instead of percentiles is to get a higher number of observations for each group when individuals are ranked by welfare level. For example, if a percentile contains only 50 individuals (ranked by welfare) and if we assign to these percentiles the respective mean years of education, then it is possible to obtain huge variations within each percentile, which results in very wide confidence intervals between the growth in the two periods, and we will not be able to make precise statements about the welfare gradient.

8 This is also of relevance when evaluating distributional impacts of aid and public spending. Standard benefit incidence studies, for example, analyze the impact of public spending by calculating shares of the total spending to each percentile and comparing the shares of the income poorest with the income richest centile (e.g., Van de Walle, 1998; Van de Walle and Nead, 1995; Lanjouw and Ravallion, 1998; Roberts, 2003). But the share of public spending for the poor serves only as a proxy for a real welfare impact in terms of non-income achievements. For example, it provides an instrument to assess if public social spending programs has reached the targeted income-poorest population groups and if the public resources are effective allocated and used. For example, Berthélemy (2005) shows that education policies in Sub-Saharan Africa are biased against the poor. On average, policies favor the non-poor because they are concentrated on improvements in secondary and tertiary education and only little attention is paid to improvements in primary education completion, i.e., to the poor population.
} 
growth, even though the absolute increments are 0.2 years for the poor and 1 year for the rich. As discussed in detail in Klasen (2008), it is more plausible and empirically much more common to consider absolute improvements when studying non-income dimensions of well-being such as education.

Accordingly, we define 'pro-poor change' (PPCH) as the area under the absolute GIC up to the headcount $\mathrm{H}$. The PPCH is formally expressed by

$$
P P C H=c_{t}^{p}=\frac{1}{H_{t-1}} \sum_{1}^{H_{t}} c_{t}(p)
$$

where $c_{t}$ shows the absolute change of the respective indicator for each centile and which is equivalent to the mean of the changes of the poor up to the headcount. We compare the PPCH with the change in mean (CHIM), which is defined by

$$
C H I M=\delta_{t}=\mu_{t}-\mu_{t-1}
$$

If the PPCH exceeds 0 everywhere, we have weak absolute pro-poor growth. If the PPCH exceeds the CHIM, growth is declared to be pro-poor in the strong absolute sense. As we are considering non-income indicators only, we will focus particularly on the comparison of the PPCH and the $\mathrm{CHIM}$ and thus investigate whether educational progress was pro-poor in the weak absolute or strong absolute sense.

\section{Data}

We use nationally representative Demographic and Health Surveys (DHS) for 37 countries at different points in time. Besides information about household socio-economic characteristics, health, nutrition and infrastructure, the DHS data sets include also several indicators on education both for children and adults. Table 1 in the appendix provides an overview about the countries and periods for which we use the DHS data sets for the analysis. For 24 countries, we have data sets for 3 periods. This allows not only to capture changes in the access to the education system and in educational outcomes over time, but also to examine and analyze differences in these changes between the pre- and post-Dakar periods in the distribution of access and outcomes of education by welfare groups as well as by the other background characteristics such as urban and rural areas and/or by gender. For 13 countries we still have two periods allowing examining changes over time. Is sum, we analyze 98 DHS data sets. 
As key indicator of educational access, we use the net attendance rates for secondary education based on the respective country specific agebracket for secondary education. The net attendance rate of secondary education is calculated as the number of children in the relevant age bracket that are attending secondary school divided by the size of the relevant age bracket. Children of other ages enrolled in secondary education are not taken into account. As the net attendance rate covers only the children in the official age range that is associated with a given level of education, the net attendance rate is also an indicator of the functional capability of the educational system. A high net attendance rate is only possible if the education system has the capacity to educate entire cohorts and allow them to enter and progress through the school system according to their age?

To assess the educational attainment in each country and across the welfare distribution within countries, we use two different indicators. First, we use average years of schooling completed and, second, the completion rates of secondary education. Since educational attainment does not change much in adulthood, we therefore restrict the sample to a specific cohort of young adults aged between 17 and 22 to better monitor changes over time. Clearly, the secondary completion rates for this age bracket can only be high if most children of an age cohort enter secondary school at the right age and complete according to their age. If children are delayed in entry or progress slowly, many will not have completed secondary schooling in this age bracket. This should be borne in mind when interpreting the results ${ }^{10}$.

\section{Results}

In the sample of countries we analyze in this paper, a large heterogeneity in terms of their level of human development is observable. Appendix Table 2 shows large differences in the level of per capita GDP and poverty rates. The level of GDP per capita ranges from 646 USD PPP in Malawi (2004) to 7304 USD PPP in Colombia (2005); it similarly spans a wide diversity of countries when considering the broader Human Development Index.

\footnotetext{
9 The gross attendance rate would also include children outside of the age range in the numerator (and use the same denominator). In countries where many children enter the school system late or progress slowly, the differences between the gross and net enrolment ratios can be large. See also discussion below.

${ }^{10}$ We did our analysis also for the age group of adults aged 23-27. Besides an overall lower level of education, the distribution of improvements shows very similar results as for the younger age group.
} 


\subsection{Within Country Educational Inequality}

We start by showing some data on educational inequalities in our country sample at one point in time. In particular, Figure 1 and Figure 2 provide an overview of the within country distribution of net attendance rates in secondary education for children in the respective official age range, for secondary education completion rates of adults aged between 17 and 22 by asset index quintiles as well as the mean value for each country using the latest year available ${ }^{11}$.

Figure 1 - Same Country Different World: Net Attendance Rates for Secondary Education by Asset Index Quintiles

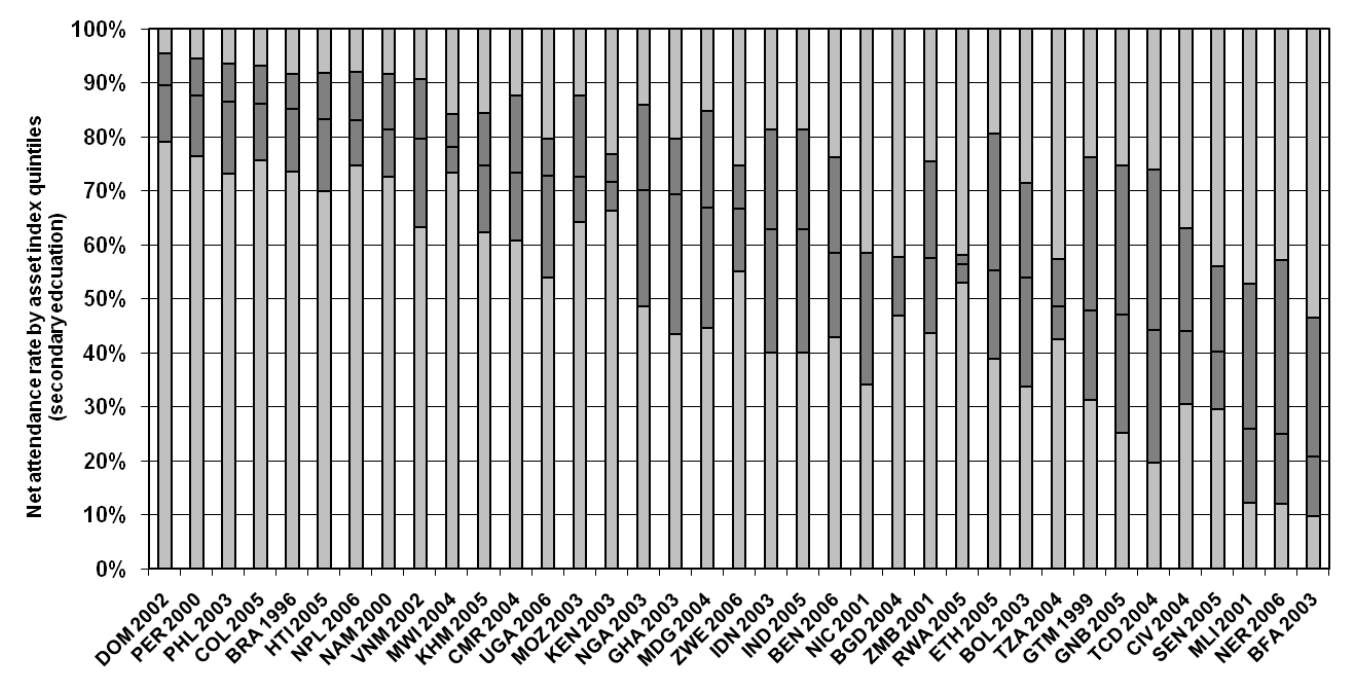

Source: Demographic and Health Surveys (DHS); own calculations.

${ }^{11}$ Figures 1 and 2 show for each country the variation in the respective educational indicator between the first quintile (the poorest population sub-group) marked by the lower end of the dark colored bar and the fifth quintile (the richest population sub-group) marked by the upper end of the dark colored bar as well as the mean value of the respective indicators marked by the line within the dark colored bar. 
Figure 2 - Same Country Different World: Secondary Education Completion Rates by Asset Index Quintiles

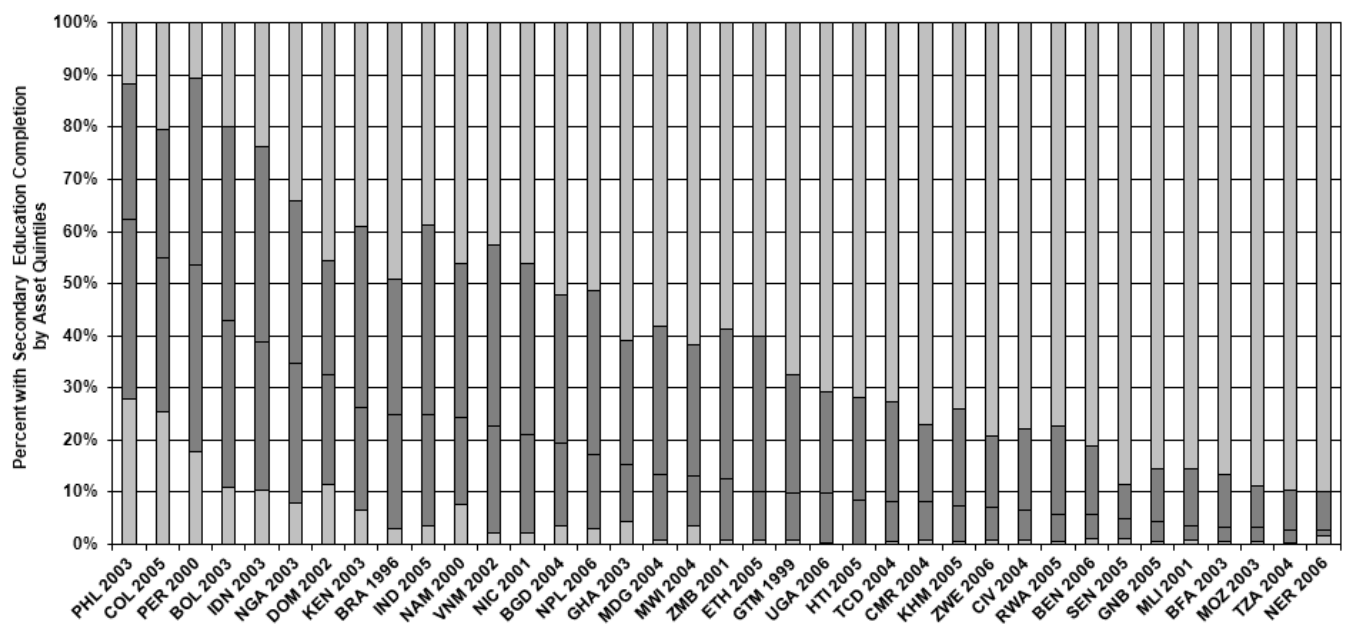

Source: Demographic and Health Surveys (DHS); own calculations.

Both Figures, which are sorted by declining mean attendance (completion) rates, clearly show vast inequalities in secondary attendance and completion rates by asset quintiles, often reaching 30 percentage points or more. But there are interesting differences in these inequalities. In particular, inequalities in attendance rates are particularly large in countries with low overall attendance rates, while the gaps shrink in those countries where overall attendance is higher. While the decline in inequality is partly related to the upward bound of net attendance rates of $100 \%$, inequality is lower even in countries which are far from reaching $100 \%$ attendance in the richest quintile. In contrast, when it comes to secondary completion rates, the converse picture appears and now inequalities are larger in countries where overall attendance is higher. The stark contrast between the two indicators can suggest one of the following interpretations. Since the secondary completion rates for 17-22 year olds are a backward looking indicator measuring the recent performance of the educational system while the attendance rates measure current performance, these differences could suggest that the low inequality in attendance rates will soon close the still-existing vast inequalities in completion rates. Alternatively, this could suggest that countries that are successful in boosting overall attendance and closing the attendance gap are still far from successful in closing the completion gap, i.e., many of the poorer children attending will not complete secondary education. Conversely, in education-poor countries the completion gap is still small as even the rich have only low completion rates. Judging from historical trends, this latter interpretation is more likely. If one examines 
development of educational inequality over time (see appendix tables 3-5), one sees that large inequalities in educational completion rates in countries with higher educational achievements have co-existed with relatively small gaps in attendance for quite some time in many countries (see, e.g., Philippines, Peru, Brazil, Namibia, and Kenya) ${ }^{12}$. Thus, not only are countries with high levels of attendance (still) unable to close the completion gap; but in education-poor countries, the large attendance gaps will ensure rising completion gaps in future, unless policy intervenes to reduce these gaps! Thus it is indeed important to study who benefits from educational expansion, a topic to which we now turn.

Figure 3 relates inequality in secondary attendance between the rich and the poor (proxied by the ratio of the richest to the poorest quintiles) to economic prosperity (measured by PPP adjusted GDP per capita) and UNDP's Human Development Index. While there is some tendency of the inequalities in educational attendance to decline as countries get richer and as their HDI improves, there is considerable variation around that trend. While inequality in attendance seems to be low at high income levels and high HDIs (as one would expect given that these countries are expected to be close to universal secondary attendance), there is dramatic variation at lower income and HDI levels. It thus appears that high inequality in attendance is not inevitable among poor countries and probably greatly depends on educational policies, an issue to which we return below ${ }^{13}$.

\footnotetext{
${ }^{12}$ In some countries, such as Colombia and the Dominican Republic, achievement gaps are coming down in line with attendance gaps, pointing to more hopeful trends in these countries.

${ }^{13}$ Since the HDI also includes the combined gross enrolment rate for primary, secondary, and tertiary education (for children 6-23) as one of its components (with a weight of 1/9), the stronger relationship in the lower part of Figure 3 might be partly driven by a negative relationship between overall attendance and inequality in attendance.
} 
Figure 3 - Correlation Between Net Attendance Rates, HDI, and GDP per Capita
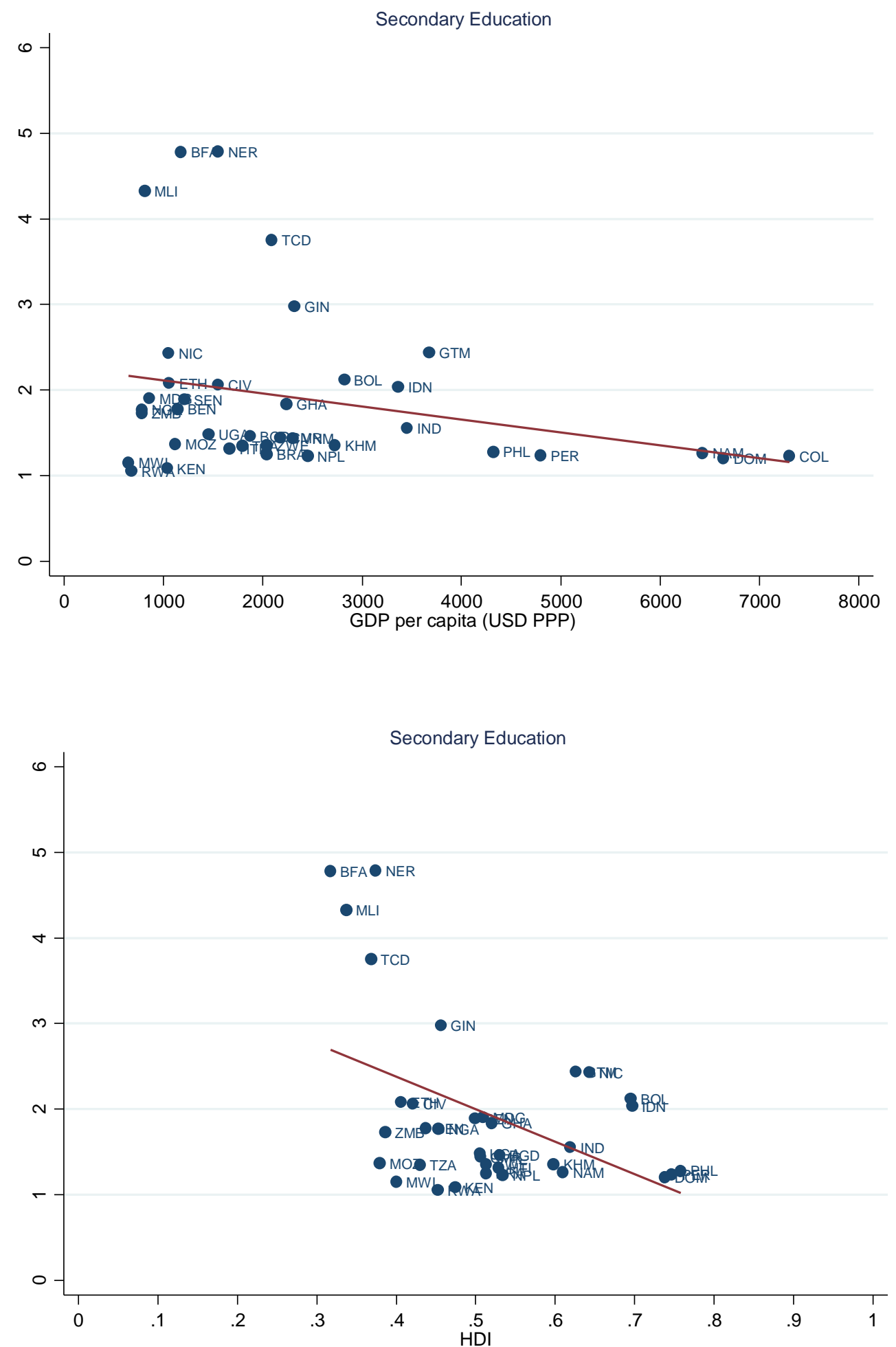

Source: Demographic and Health Surveys (DHS), World Bank (2007); own calculations. Note: for the Country abbreviations see Table A1 in the Appendix. 
Appendix Tables 3-5 present the respective numbers of all educational indicators by asset index quintiles for all survey year. They also include the means, i.e., net attendance rates for secondary education and secondary education completion rates, as well as the ratio of the fifth to the first quintile as a direct indicator of inequality between the richest and the poorest population subgroup.

Appendix Table 3 concretizes the within country differences illustrated in Figure 2. 15 countries have had a quintile five to one ratio in secondary attendance of more than 2 in the first period. The five countries with the highest educational inequality in the first period were Mali (9.042), Burkina Faso (8.449), Senegal (6.553), and Guinea (4.178). When looking at the latest available survey year, the five countries with the highest inequality in net attendance in secondary education between the first and the fifth asset index quintile are Burkina Faso (4.878), Mali (4.673), Niger (4.617), and Chad (3.717). Two of them, Burkina Faso and Mali, have also been among the countries with the highest educational inequality in the base year. Conversely, inequality is much lower and declining quite rapidly in most Asian and Latin American countries and some countries in Sub Saharan Africa, including Tanzania, Zimbabwe, Kenya, Malawi and Namibia. The results are quite similar when examining inequality in years of schooling or inequality in secondary completion rates.

The results from Tables 3-5 also reveal implications regarding possible policy priorities. In countries where the mean attendance rates are already quite high such as Bolivia, Peru, Nicaragua, Vietnam, India, Namibia, Philippines, or Brazil, supply-side interventions are unlikely to improve access to education of the poor by much. Although attendance rates for the poor are very low, the relatively high mean rates show that, in general, schools do exist. Therefore, the high inequality in attendance rates and years of schooling could suggest the need for more interventions to ensure that the poor are able to enter and progress in the school system according to their age, as well as for demand-side interventions to accelerate incentives for the poor to send their children to school. In the other countries, a mix of improvements for the poor in terms of access, progression through the school system, and demand-side interventions are required to ensure rising educational attendance and achievements for the poor.

\subsection{Pro-Poor Educational Progress?}

Before analyzing whether countries experienced a pro-poor development in education over time, we start by looking at mean changes in education within countries. Appendix Table 3 shows that for 36 countries net attendance rates in secondary education have been improving between the base year and the most recent available survey 
year $^{14}$. Only Burkina Faso and Namibia have experienced a decline in the mean net attendance rates in secondary education.

Looking at improvements in educational achievements, Table A4 also shows an overall positive development, although not as positive as with attendance rates. Only Burkina Faso, Cote d'Ivoire, Ghana, Kenya, Mozambique, and Rwanda have experienced a decline in average years of education. The highest mean improvements in average years of education have been made in Madagascar with an improvement of more than five years between 1992 and 2004. Also Table A5 shows overall even lower progress in secondary completion rates. Now about half of Sub-Saharan African countries have experienced a decline in completion rates and progress between the two episodes is highly uneven. In other regions, the trend is overall more positive, but also slower than using the other indicators. This slower progress is not very surprising as it is much easier to boost secondary attendance rates than to ensure that children complete secondary schooling at the right age.

As discussed above, we focus our analysis on comparisons between the mean absolute improvements (CHIM) and pro-poor change (PPCH) ${ }^{15}$. To synthesize the most important developments, we cluster the countries in three groups for which we compare the pro-poorness in access to education and in educational outcome. First, we compare country episodes with a very low level of educational attendance in the base year (defined as a net attendance rate lower than 1/3 and marked in bold in the Tables 1-3 below) with country episodes that already have had a quite high base level ${ }^{16}$. Second, we compare the pro-poorness of country episodes that have experienced high average improvements (underlined in Tables 1-3) with country episodes that have experienced low average improvements. Third, we compare the pro-poorness of countries in different regions of the developing world (with African countries marked in italics).

Looking at the countries with a low base level in net attendance rates in secondary education, Table 1 shows for each country and period the change in mean (CHIM), the pro-poor change $(\mathrm{PPCH})$, the growth rate of

\footnotetext{
${ }^{14}$ Note that for Bolivia the pro-poor progress for the second period was dropped for net attendance rates in secondary education. This is because there is a huge decline in attendance rates in the data sets (also at the official publication on the survey), which is likely to be a measurement error, since educational outcomes have been improved substantially in all periods.

${ }^{15}$ Please note that whenever the PPCH=CHIM we consider this also a pro-poor episode in the strong absolute sense. This is rare in most of the Tables, but occurs more frequently in Table 3.

16 We use the attendance variable for grouping country performance of all three indicators of educational progress to facilitate comparisons.
} 
the first and fifth quintile and the ratio of the growth rates of the fifth to the first quintile for the net attendance rate in secondary education.

Table 1 - Pro-Poor Educational Progress (Net Attendance Rate - Secondary Education)

\begin{tabular}{|c|c|c|c|c|c|c|}
\hline Country & Period & CHIM & PPCH & Quintile 1 & Quintile 5 & Ratio 5:1 \\
\hline \multirow{2}{*}{ Bangladesh } & 1993-1999 & 5.8 & 7.0 & 12.7 & 0.6 & 0.0 \\
\hline & 1999-2004 & -1.8 & 0.3 & -2.4 & -3.2 & 1.3 \\
\hline \multirow{2}{*}{ Benin } & 1996-2001 & 13.0 & 13.9 & 14.9 & 11.7 & 0.8 \\
\hline & $\underline{2001-2006}$ & 12.4 & 12.8 & 13.6 & 11.7 & 0.9 \\
\hline Bolivia & 1994-1998 & 6.7 & 8.3 & 6.2 & 3.2 & 0.5 \\
\hline Brazil & $\underline{1991-1996}$ & 19.3 & 30.9 & 32.2 & 9.3 & 0.3 \\
\hline \multirow{2}{*}{ Burkina Faso } & 1992-1998 & -6.7 & -1.8 & -0.5 & -5.7 & 12.5 \\
\hline & $1998-2003$ & 3.9 & 4.8 & 4.0 & 0.0 & 0.0 \\
\hline Cambodia & $\underline{2000-2005}$ & 15.8 & 16.8 & 16.1 & 8.5 & 0.5 \\
\hline \multirow{2}{*}{ Cameroon } & 1991-1998 & -2.8 & -1.0 & 0.3 & -5.1 & -15.0 \\
\hline & $\underline{1998-2004}$ & 10.4 & 15.5 & 17.5 & 5.6 & 0.3 \\
\hline Chad & 1996-2004 & 6.7 & 0.7 & -2.4 & 13.5 & -5.6 \\
\hline \multirow{2}{*}{ Colombia } & $1995-2000$ & 1.3 & 3.4 & 3.0 & -3.1 & -1.0 \\
\hline & 2000-2005 & 4.7 & 8.2 & 9.6 & 3.8 & 0.4 \\
\hline \multirow{2}{*}{ Cote d'Ivoire } & 1994-1999 & 2.6 & 1.1 & 4.8 & 2.2 & 0.5 \\
\hline & 1999-2004 & 2.7 & 4.6 & 3.7 & 4.1 & 1.1 \\
\hline \multirow{2}{*}{$\begin{array}{l}\text { Dominican } \\
\text { Republic }\end{array}$} & 1991-1996 & 8.9 & 12.9 & 11.0 & 3.7 & 0.3 \\
\hline & 1996-2002 & 6.1 & 9.1 & 10.8 & 4.1 & 0.4 \\
\hline Ethiopia & 1998-2005 & 13.7 & 11.7 & 9.7 & 6.1 & 0.6 \\
\hline \multirow{2}{*}{ Ghana } & 1993-1998 & 0.4 & -6.3 & -6.7 & 8.1 & -1.2 \\
\hline & 1998-2003 & 3.4 & 5.3 & 3.2 & -1.2 & -0.4 \\
\hline Guatemala & 1995-1999 & 7.2 & 8.8 & 8.4 & 6.3 & 0.8 \\
\hline Guinea & 1999-2005 & 21.9 & 18.4 & 14.4 & 28.0 & 1.9 \\
\hline \multirow{2}{*}{ Haiti } & $1994-2000$ & -5.6 & 11.4 & 14.6 & -45.1 & -3.1 \\
\hline & $\underline{2000-2005}$ & 13.2 & 1.8 & 3.2 & 46.6 & 14.4 \\
\hline \multirow{2}{*}{ India } & 1992-1999 & 25.7 & 20.5 & 19.7 & 34.9 & 1.8 \\
\hline & 1999-2005 & 7.2 & 11.1 & 10.7 & 1.9 & 0.2 \\
\hline \multirow{2}{*}{ Indonesia } & 1991-1997 & 7.9 & 10.1 & 7.5 & 3.7 & 0.5 \\
\hline & 1997-2003 & 1.7 & 0.4 & -1.2 & 0.4 & -0.3 \\
\hline \multirow[t]{2}{*}{ Kenya } & 1993-1998 & -1.4 & 0.0 & 0.6 & -3.2 & -5.2 \\
\hline & 1998-2003 & -3.1 & -8.3 & -12.1 & -1.2 & 0.1 \\
\hline
\end{tabular}

Table continues on next page. 
Table 1 - continued

\begin{tabular}{|c|c|c|c|c|c|c|}
\hline Country & Period & CHIM & PPCH & "Quintile 1 & Q Quintile 5 & Ratio 5:1 \\
\hline \multirow{2}{*}{ Madagascar } & 1992-1997 & -4.4 & -3.0 & -1.1 & -4.5 & 4.1 \\
\hline & 1997-2004 & 21.6 & 20.0 & 15.4 & 7.4 & 0.5 \\
\hline \multirow{2}{*}{ Malawi } & $1992-2000$ & 9.0 & 14.6 & 16.4 & 4.2 & 0.3 \\
\hline & $2000-2004$ & 1.6 & 2.7 & 2.6 & -0.4 & -0.1 \\
\hline Mali & 1996-2001 & 5.8 & 7.0 & 7.2 & 4.6 & 0.6 \\
\hline Mozambique & $\underline{1997-2003}$ & 15.4 & 18.3 & 20.1 & 11.5 & 0.6 \\
\hline Namibia & $1992-2000$ & -4.8 & -9.7 & -12.1 & 2.2 & -0.2 \\
\hline \multirow{2}{*}{ Nepal } & 1996-2001 & 8.6 & 9.8 & 3.1 & 2.4 & 0.8 \\
\hline & $\underline{2001-2006}$ & 12.8 & 17.2 & 21.2 & 5.1 & 0.2 \\
\hline Nicaragua & $1997-2001$ & 1.0 & 3.1 & 4.2 & -0.5 & -0.1 \\
\hline \multirow{2}{*}{ Niger } & 1992-1998 & -4.0 & -0.9 & -1.0 & -4.6 & 4.6 \\
\hline & 1998-2006 & 9.2 & 7.8 & 6.3 & 12.1 & 1.9 \\
\hline Nigeria & $1999-2003$ & 4.4 & 7.8 & 2.9 & 0.1 & 0.0 \\
\hline \multirow{2}{*}{ Peru } & $1992-1996$ & 2.9 & 2.2 & 4.8 & 6.2 & 1.3 \\
\hline & $1996-2000$ & 1.2 & 2.2 & 4.7 & -0.1 & 0.0 \\
\hline \multirow{2}{*}{ Philippines } & 1993-1998 & -3.0 & -2.6 & -1.8 & -3.7 & 2.1 \\
\hline & 1998-2003 & 2.1 & 2.1 & 1.1 & 2.6 & 2.4 \\
\hline \multirow{2}{*}{ Rwanda } & $1992-2000$ & -10.8 & -3.1 & -4.3 & -28.6 & 6.6 \\
\hline & $\underline{2000-2005}$ & 36.9 & 34.2 & 33.6 & 38.3 & 1.1 \\
\hline Senegal & 1992-2005 & 18.8 & 23.4 & 21.8 & 8.8 & 0.4 \\
\hline \multirow{2}{*}{ Tanzania } & 1992-1996 & 10.2 & 11.9 & 9.6 & 4.2 & 0.4 \\
\hline & 1996-2004 & 1.6 & -1.9 & -1.8 & 10.8 & -6.1 \\
\hline \multirow{2}{*}{ Uganda } & $\underline{1995-2000}$ & 18.5 & 24.3 & 23.3 & 12.3 & 0.5 \\
\hline & $2000-2006$ & 1.4 & -4.0 & -12.7 & 4.8 & -0.4 \\
\hline Vietnam & 1997-2002 & 7.3 & 10.6 & 7.0 & 0.8 & 0.1 \\
\hline \multirow{2}{*}{ Zambia } & 1992-1996 & -2.2 & -2.9 & -3.6 & -0.1 & 0.0 \\
\hline & $1996-2001$ & 6.5 & 7.7 & 5.7 & 2.3 & 0.4 \\
\hline \multirow[t]{2}{*}{ Zimbabwe } & 1994-1999 & 2.3 & 1.3 & 2.6 & 5.9 & 2.3 \\
\hline & $1999-2006$ & -0.4 & -2.3 & -6.0 & 0.0 & 0.0 \\
\hline
\end{tabular}

Source: Demographic and Health Surveys; own calculations.

Note: The different country episode formats refer to different clusters with respect to educational levels in the base year, their rate of improvement, and the region. Country episodes marked in bold refer to country episodes that show very low levels in education (net enrolment below $1 / 3$ ) in the base year. Underlined country episodes refer to very large improvements (increase greater than 10 percentage points). Countries in italics refer to countries from SubSaharan Africa (for underlying data, see Table A3).

Interesting to note is that of the 19 country episodes with a very low base level, only for 8 country episodes the (positive) PPCH exceeds the (positive) CHIM, indicating weak and strong absolute pro-poor progress in access to education and thus declining absolute inequality in enrolment rates. In a further 4 country episodes, both the $\mathrm{PPCH}$ and the CHIM are negative, with the latter being more negative, thus signifying a pro-poor contraction in educational enrolments. In the remaining 7 country episodes the positive CHIM exceeds the positive $\mathrm{PPCH}$, indicating weak 
absolute but no strong absolute pro-poor educational progress. In the post-Dakar period, things have improved in the sense that in all 8 country episodes for this group of countries, educational progress was pro-poor in the weak absolute sense (i.e., $\mathrm{PPCH}>0$ ), but not noticeably more pro-poor in a strong absolute sense. In fact, in only 3 out of 8 episodes, the PPCH was greater than the CHIM, while the reverse was the case in the remaining 5 .

Looking at the remaining country episodes (where initial secondary enrolment was above 1/3), things look slightly more positive although also here there is considerably heterogeneity. Of the 41 country episodes in this group, in 28 the positive $\mathrm{PPCH}$ exceeded the positive CHIM signifying weak and strong absolute pro-poor progress and therefore declining absolute inequality in net attendance rates. In a further 6 episodes, both the PPCH and the CHIM were negative, in 4 of which these educational contractions were anti-poor (PPCH $<\mathrm{CHIM})$. In 7 episodes, the positive CHIM exceeded the PPCH, i.e., there was weak absolute but no strong absolute pro-poor progress. There is therefore a preponderance of episodes of strong absolute pro-poor progress (and thus declining absolute inequality), particularly in episodes of educational expansion. Thus in countries where secondary educational attendance is already substantial, it appears that countries succeed more in extending this access to poorer population groups than in countries where attendance rates are still very low. At the same time, also here there is significant heterogeneity and it is far from automatic that improvements will be pro-poor. ${ }^{17}$ Particularly worrying is also that declines in attendance often hit the poor more than the non-poor.

Second, we examine country episodes with particularly large progress in attendance rates (underlined in Table 1) to see whether they are more or less pro-poor. In Table 1 it is clear that among episodes with fast overall progress in attendance rates, pro-poor episodes predominate (in 10 the $\mathrm{PPCH}>\mathrm{CHIM}$, in 6 the reverse is the case); but this is even more the case in episodes where progress was not particularly large. Here the $\mathrm{PPCH}>\mathrm{CHIM}$ in 26 cases where both are positive, while the reverse is only the case in 9 cases. If anything, fast progress appears to be less pro-poor as slower progress, although again heterogeneity within each group is large.

Third, looking at region specific differences in pro-poor educational progress, we concentrate on differences between Sub-Sahara Africa (italics in Table 1). Here, the trend is clearer both in terms of absolute progress as

${ }^{17}$ This is not primarily driven by the fact that richer groups already have close to $100 \%$ net attendance and thus further educational progress must automatically be more propoor. In no country was secondary net attendance above $95 \%$ for the richest quintile in the first year; in most countries it was considerably below $90 \%$, leaving significant further scope for improvements. 
well as pro-poor progress. In non-African countries, episodes of pro-poor progress in attendance rates clearly predominate. In all 24 country episodes, there is pro-poor progress in the weak absolute sense; in addition, in 20 of them the PPCH $>\mathrm{CHIM}$, indicating strong absolute progress and declining absolute inequality in attendance rates. In contrast, in Africa, there is tremendous heterogeneity: in 16 country episodes, progress is pro-poor in a weak and strong absolute sense; in 10 episodes it is anti-poor in a strong absolute sense, and in nine episodes both the PPCH and the CHIM are negative.

When examining pro-poor progress in secondary completion rates (Table 2), things look considerably worse overall for all groups, both in terms of absolute changes as well as in terms of pro-poor progress.

Table 2 - Pro-Poor Educational Progress (Secondary Education Completion - Age group 17-22)

\begin{tabular}{|c|c|c|c|c|c|c|}
\hline Country & Period & CHIM & PPCH & Quintile 1 & Quintile 5 & Ratio $5: 1$ \\
\hline \multirow{2}{*}{ Bangladesh } & 1993-1999 & 6.4 & 1.0 & 2.5 & 13.7 & 5.5 \\
\hline & 1999-2004 & -3.3 & 1.0 & 0.2 & -11.3 & -55.8 \\
\hline \multirow{2}{*}{ Benin } & 1996-2001 & 0.6 & -0.4 & -1.1 & 3.0 & -2.8 \\
\hline & 2001-2006 & 2.1 & 0.9 & 1.1 & 6.2 & 5.7 \\
\hline Bolivia & 1994-1998 & 6.1 & 2.9 & 2.1 & 2.4 & 1.2 \\
\hline Brazil & $\underline{1991-1996}$ & 14.8 & 4.4 & 1.4 & 28.1 & 19.6 \\
\hline \multirow{2}{*}{ Burkina Faso } & 1992-1998 & -0.7 & -0.1 & 0.0 & -2.8 & -85.3 \\
\hline & 1998-2003 & 0.0 & -0.3 & -0.4 & 1.4 & -3.8 \\
\hline Cambodia & $\underline{2000-2005}$ & 1.8 & 0.3 & 0.2 & 5.0 & 24.2 \\
\hline \multirow{2}{*}{ Cameroon } & 1991-1998 & 0.2 & 0.4 & 1.0 & -1.2 & -1.2 \\
\hline & 1998-2004 & -0.7 & -0.7 & -1.2 & -0.8 & 0.6 \\
\hline Chad & 1996-2004 & 2.0 & -0.5 & -0.8 & 8.9 & -11.3 \\
\hline \multirow{2}{*}{ Colombia } & $1995-2000$ & 13.9 & 10.4 & 7.5 & 12.4 & 1.6 \\
\hline & $2000-2005$ & 5.2 & 5.5 & 6.7 & 13.9 & 2.1 \\
\hline \multirow{2}{*}{ Cote d'Ivoire } & 1994-1999 & 4.4 & 1.1 & 1.5 & 11.1 & 7.5 \\
\hline & 1999-2004 & -4.2 & -0.8 & -1.0 & -9.6 & 9.7 \\
\hline \multirow{2}{*}{$\begin{array}{l}\text { Dominican } \\
\text { Republic }\end{array}$} & 1991-1996 & 0.7 & 0.7 & 0.4 & 4.1 & 9.5 \\
\hline & 1996-2002 & 6.1 & 4.0 & 2.8 & 5.8 & 2.1 \\
\hline Ethiopia & 1998-2005 & -0.1 & 0.0 & -0.2 & -1.3 & 8.1 \\
\hline \multirow{2}{*}{ Ghana } & 1993-1998 & -1.5 & 0.3 & 0.4 & -7.5 & -17.0 \\
\hline & 1998-2003 & 6.6 & 1.4 & 2.0 & 19.7 & 9.9 \\
\hline
\end{tabular}

Table continues on next page. 
Table 2 - continued

\begin{tabular}{|c|c|c|c|c|c|c|}
\hline Country & Period & CHIM & PPCH & Quintile 1 & Quintile 5 & Ratio $5: 1$ \\
\hline Guatemala & 1995-1999 & 0.7 & 0.2 & 0.1 & 0.4 & 2.8 \\
\hline Guinea & 1999-2005 & -1.1 & -1.1 & -1.7 & -1.3 & 0.8 \\
\hline \multirow{2}{*}{ Haiti } & $1994-2000$ & -3.4 & -2.5 & -3.3 & -6.0 & 1.8 \\
\hline & $\underline{2000-2005}$ & 1.3 & -0.3 & -0.4 & 4.9 & -12.0 \\
\hline \multirow{2}{*}{ India } & 1992-1999 & 18.7 & 8.7 & 6.4 & 30.5 & 4.7 \\
\hline & $1999-2005$ & -10.8 & -6.8 & -5.9 & -18.0 & 3.1 \\
\hline \multirow{2}{*}{ Indonesia } & 1991-1997 & 0.8 & -0.3 & -0.1 & 1.5 & -17.4 \\
\hline & $1997-2003$ & 8.9 & 4.5 & 2.2 & 11.5 & 5.3 \\
\hline \multirow[t]{2}{*}{ Kenya } & 1993-1998 & 14.2 & 6.6 & 5.3 & 30.0 & 5.7 \\
\hline & 1998-2003 & 0.8 & -2.2 & -2.2 & 9.7 & -4.4 \\
\hline \multirow{2}{*}{ Madagascar } & 1992-1997 & -1.7 & -2.2 & -1.8 & -0.8 & 0.5 \\
\hline & 1997-2004 & 4.6 & 0.2 & 0.5 & 12.7 & 26.4 \\
\hline \multirow{2}{*}{ Malawi } & $1992-2000$ & 1.3 & 0.3 & 0.6 & 5.4 & 8.9 \\
\hline & $2000-2004$ & 2.4 & 1.6 & 0.6 & 7.4 & 12.4 \\
\hline Mali & 1996-2001 & 0.7 & 0.4 & 0.1 & 1.9 & 21.3 \\
\hline Mozambique & 1997-2003 & -1.4 & -1.6 & -1.7 & -2.1 & 1.3 \\
\hline Namibia & $1992-2000$ & 9.1 & 2.7 & 1.8 & 18.9 & 10.4 \\
\hline \multirow{2}{*}{ Nepal } & 1996-2001 & 3.6 & 0.2 & -0.9 & 13.1 & -15.0 \\
\hline & $\underline{2001-2006}$ & 4.6 & 0.8 & 1.4 & 10.4 & 7.5 \\
\hline Nicaragua & $1997-2001$ & -0.2 & -0.2 & -0.5 & 2.3 & -4.4 \\
\hline \multirow{2}{*}{ Niger } & 1992-1998 & -0.3 & 0.1 & -0.6 & -1.4 & 2.4 \\
\hline & 1998-2006 & 0.1 & -0.3 & 0.4 & 1.7 & 3.9 \\
\hline Nigeria & 1999-2003 & -1.4 & -6.1 & -7.0 & 7.6 & -1.1 \\
\hline \multirow{2}{*}{ Peru } & $1992-1996$ & -4.3 & -3.7 & -2.0 & -1.0 & 0.5 \\
\hline & $1996-2000$ & 2.5 & 2.1 & 3.2 & 4.9 & 1.5 \\
\hline \multirow{2}{*}{ Philippines } & 1993-1998 & -25.8 & -18.7 & -13.5 & -29.2 & 2.2 \\
\hline & $1998-2003$ & 29.7 & 21.1 & 13.0 & 33.5 & 2.6 \\
\hline \multirow{2}{*}{ Rwanda } & 1992-2000 & -0.2 & -0.3 & -0.5 & 1.6 & -3.2 \\
\hline & $\underline{2000-2005}$ & 0.6 & 0.1 & 0.2 & 1.5 & 8.9 \\
\hline Senegal & 1992-2005 & -0.8 & -0.4 & 0.2 & -3.1 & -18.3 \\
\hline \multirow{2}{*}{ Tanzania } & $\underline{1992-1996}$ & 0.5 & 0.3 & 0.3 & 1.0 & 3.6 \\
\hline & 1996-2004 & 0.1 & -0.2 & -0.1 & 1.3 & -23.5 \\
\hline \multirow{2}{*}{ Uganda } & 1995-2000 & -4.3 & -1.6 & -1.7 & -12.1 & 7.2 \\
\hline & $2000-2006$ & -0.2 & 0.8 & 1.0 & -1.0 & -1.0 \\
\hline Vietnam & $1997-2002$ & 6.5 & 4.3 & 1.5 & 8.6 & 5.6 \\
\hline \multirow{2}{*}{ Zambia } & 1992-1996 & -4.3 & -0.7 & -0.6 & -13.1 & 21.4 \\
\hline & $1996-2001$ & 5.5 & 0.7 & 0.3 & 18.1 & 69.8 \\
\hline \multirow[t]{2}{*}{ Zimbabwe } & 1994-1999 & 30.2 & 15.3 & 12.6 & 59.9 & 4.8 \\
\hline & 1999-2006 & -0.4 & -2.5 & -6.2 & -0.2 & 0.0 \\
\hline
\end{tabular}

Source: Demographic and Health Surveys; own calculations.

Note: The different country episode formats refer to different clusters with respect to educational levels in the base year, their rate of improvement, and the region. Country episodes marked in bold refer to country episodes that show very low levels in education (net enrolment below $1 / 3$ ) in the base year. Underlined country episodes refer to very large improvements (increase greater than 10 percentage points). Countries in italics refer to countries from SubSaharan Africa (for underlying data, see Table A5). 
Also, there seem to be relatively few differences between the different groups. Table 2 shows, for example, that of the 19 country episodes with low initial attendance, the positive $\mathrm{PPCH}$ for secondary completion rates was larger than the positive CHIM in only 2 cases, indicating weak and strong absolute pro-poor progress. In a further 5 episodes, both are negative, four of which are pro-poor contractions (and one episode an anti-poor contraction). In the other 12 episodes, the PPCH was smaller than the positive CHIM, i.e., we have weak absolute but no strong absolute pro-poor growth, with absolute educational inequalities widening. When examining the 41 country episodes with higher initial attendance, there are 6 instances of pro-poor progress, a further 7 instances of pro-poor contractions, 2 anti-poor contractions, and 26 episodes of rising absolute inequality. Similarly, if we cut the data by fast progress in attendance or by region, the instances of $\mathrm{PPCH}$ is smaller than the CHIM in the vast majority of cases in all groups. Thus in total progress in secondary completion rates was much slower than in attendance, and it was much less pro-poor across all groups we consider with great heterogeneity within each group.

When examining progress in total years of schooling (Table 3), the results are slightly more positive in terms of more episodes of overall progress, and of pro-poor progress in the strong absolute sense. Again the same differentials among groups as in Table 1 emerge. Progress in years of schooling was more pro-poor, particularly in the strong absolute sense in country episodes higher initial attendance rates, with lower rates of overall progress in attendance, and in countries outside of Africa.

Table 3 - Pro-Poor Educational Progress (Average Years of Education - Age group 1722)

\begin{tabular}{llrrrrr}
\hline \hline Country & Period & CHIM & PPCH & Quintile 1 & Quintile 5 & Ratio 5:1 \\
\hline \multirow{2}{*}{ Bangladesh } & $\mathbf{1 9 9 3 - 1 9 9 9}$ & 1.3 & 1.0 & 1.4 & 1.0 & 0.7 \\
\cline { 2 - 7 } & $1999-2004$ & 0.2 & 0.7 & 0.6 & -0.4 & -0.7 \\
\hline \multirow{2}{*}{ Benin } & $\mathbf{1 9 9 6 - 2 0 0 1}$ & 0.8 & 0.5 & 0.5 & 1.3 & 2.4 \\
\cline { 2 - 7 } & $\mathbf{2 0 0 1 - 2 0 0 6}$ & 1.1 & 1.0 & 1.1 & 1.3 & 1.2 \\
\hline Bolivia & $1994-1998$ & 0.1 & 0.3 & 0.2 & -0.5 & -1.9 \\
\hline Brazil & $\underline{1991-1996}$ & 1.7 & 2.0 & 1.6 & 1.4 & 0.8 \\
\hline \multirow{2}{*}{ Burkina Faso } & $\mathbf{1 9 9 2 - 1 9 9 8}$ & -0.6 & 0.0 & 0.2 & -0.5 & -2.4 \\
\cline { 2 - 7 } & $\mathbf{1 9 9 8 - 2 0 0 3}$ & 0.4 & 0.3 & 0.1 & 0.1 & 0.7 \\
\hline Cambodia & $\underline{2000-2005}$ & 1.0 & 0.7 & 0.6 & 1.1 & 2.1 \\
\hline \multirow{2}{*}{ Cameroon } & $\mathbf{1 9 9 1 - 1 9 9 8}$ & 0.7 & 0.4 & -0.2 & 0.7 & -4.0 \\
\cline { 2 - 7 } & $\underline{1998-2004}$ & -0.5 & 0.1 & 0.3 & -0.6 & -1.7 \\
\hline Chad & $\mathbf{1 9 9 6 - 2 0 0 4}$ & 0.8 & 0.1 & -0.1 & 2.0 & -34.0 \\
\hline \hline
\end{tabular}

Table continues on next page. 
Table 3 - continued

\begin{tabular}{|c|c|c|c|c|c|c|}
\hline Country & Period & $\bar{~} \mathrm{CHIM}$ & PPCH & " Quintile 1 & "Q Quintile 5 & Ratio 5:1 \\
\hline \multirow{2}{*}{ Colombia } & $1995-2000$ & 0.9 & 1.2 & 1.3 & 0.4 & 0.3 \\
\hline & $2000-2005$ & 0.5 & 0.8 & 1.0 & 0.9 & 0.9 \\
\hline \multirow{2}{*}{ Cote d'Ivoire } & 1994-1999 & 0.7 & 0.2 & 0.1 & 1.1 & 12.0 \\
\hline & 1999-2004 & -0.9 & -0.4 & -0.2 & -1.0 & 4.5 \\
\hline \multirow{2}{*}{$\begin{array}{l}\text { Dominican } \\
\text { Republic }\end{array}$} & $1991-1996$ & 0.0 & -0.2 & -0.5 & 0.3 & -0.6 \\
\hline & 1996-2002 & 1.1 & 1.4 & 1.5 & 0.7 & 0.5 \\
\hline Ethiopia & 1998-2005 & 0.8 & 0.6 & 0.4 & 0.3 & 0.9 \\
\hline \multirow{2}{*}{ Ghana } & 1993-1998 & 0.3 & -0.4 & -0.4 & 0.8 & -2.3 \\
\hline & $1998-2003$ & -0.4 & 0.0 & 0.0 & -0.8 & 61.3 \\
\hline Guatemala & 1995-1999 & 0.4 & 0.3 & 0.1 & 0.2 & 3.3 \\
\hline Guinea & 1999-2005 & 0.7 & 0.7 & 0.4 & 0.4 & 1.0 \\
\hline \multirow{2}{*}{ Haiti } & $1994-2000$ & 0.1 & 0.7 & 1.1 & -0.2 & -0.2 \\
\hline & 2000-2005 & 0.8 & 0.6 & 0.5 & 0.7 & 1.3 \\
\hline \multirow{2}{*}{ India } & 1992-1999 & 0.6 & 0.7 & 0.7 & 0.3 & 0.5 \\
\hline & 1999-2005 & 1.1 & 1.1 & 0.9 & 0.7 & 0.7 \\
\hline \multirow{2}{*}{ Indonesia } & 1991-1997 & 0.3 & 0.4 & 0.2 & 0.3 & 1.1 \\
\hline & $1997-2003$ & 0.8 & 0.8 & 0.8 & 0.6 & 0.8 \\
\hline \multirow[t]{2}{*}{ Kenya } & 1993-1998 & 0.2 & 0.2 & 0.1 & 0.3 & 3.5 \\
\hline & $1998-2003$ & -0.4 & -1.3 & -1.6 & 0.6 & -0.4 \\
\hline \multirow{2}{*}{ Madagascar } & 1992-1997 & 3.2 & 2.0 & 1.8 & 6.6 & 3.8 \\
\hline & 1997-2004 & 1.9 & 0.1 & -0.2 & 2.5 & -12.2 \\
\hline \multirow{2}{*}{ Malawi } & $1992-2000$ & 0.9 & 1.1 & 1.1 & 0.9 & 0.8 \\
\hline & $2000-2004$ & 0.4 & 0.6 & 0.5 & 0.4 & 0.8 \\
\hline Mali & $1996-2001$ & 0.2 & 0.1 & 0.1 & 1.0 & 7.8 \\
\hline Mozambique & $\underline{1997-2003}$ & -0.1 & 0.1 & 0.1 & -0.7 & -9.8 \\
\hline Namibia & $1992-2000$ & 1.4 & 1.1 & 0.7 & 1.5 & 2.0 \\
\hline \multirow{2}{*}{ Nepal } & 1996-2001 & 0.5 & 0.2 & -0.2 & 0.8 & -3.2 \\
\hline & $\underline{2001-2006}$ & 1.1 & 0.9 & 0.9 & 1.2 & 1.4 \\
\hline Nicaragua & $1997-2001$ & 0.0 & -0.1 & -0.3 & 0.2 & -0.7 \\
\hline \multirow{2}{*}{ Niger } & 1992-1998 & 0.0 & 0.1 & 0.3 & -0.1 & -0.4 \\
\hline & 1998-2006 & 0.1 & -0.2 & -0.3 & 0.9 & -2.9 \\
\hline Nigeria & $1999-2003$ & 0.0 & 0.2 & 0.0 & 0.0 & 0.9 \\
\hline \multirow[t]{2}{*}{ Peru } & 1992-1996 & -0.5 & -0.7 & -0.5 & -0.1 & 0.2 \\
\hline & $1996-2000$ & 1.2 & 1.3 & 1.4 & 1.3 & 0.9 \\
\hline \multirow{2}{*}{ Philippines } & 1993-1998 & -0.1 & -0.2 & -0.2 & -0.2 & 0.8 \\
\hline & $1998-2003$ & 0.4 & 0.5 & 0.3 & 0.5 & 1.5 \\
\hline \multirow{2}{*}{ Rwanda } & $1992-2000$ & -0.8 & -0.6 & -0.5 & -0.5 & 1.1 \\
\hline & $\underline{2000-2005}$ & -0.4 & -0.2 & -0.4 & -0.7 & 1.8 \\
\hline Senegal & 1992-2005 & 0.3 & 0.7 & 0.7 & -0.9 & -1.3 \\
\hline \multirow{2}{*}{ Tanzania } & 1992-1996 & -0.1 & -0.1 & -0.2 & -0.1 & 0.4 \\
\hline & 1996-2004 & 0.0 & -0.6 & -0.8 & 1.0 & -1.2 \\
\hline \multirow{2}{*}{ Uganda } & 1995-2000 & 0.8 & 0.5 & 0.3 & 1.1 & 4.3 \\
\hline & $2000-2006$ & 0.1 & 0.4 & -0.2 & -0.3 & 1.8 \\
\hline Vietnam & $1997-2002$ & 0.9 & 1.1 & 1.0 & 0.5 & 0.5 \\
\hline
\end{tabular}

Table continues on next page. 
Table 3-continued

\begin{tabular}{clcrrrr}
\hline \hline Country & Period & CHIM & PPCH & Quintile 1 & Quintile 5 & Ratio 5:1 \\
\hline \multirow{2}{*}{ Zambia } & $1992-1996$ & 0.1 & 0.2 & -0.1 & 0.5 & -4.2 \\
\cline { 2 - 7 } & $1996-2001$ & 0.1 & -0.2 & -0.2 & 0.5 & -2.9 \\
\hline \multirow{2}{*}{ Zimbabwe } & $1994-1999$ & 0.4 & 0.3 & 0.4 & 0.7 & 1.5 \\
\cline { 2 - 7 } & $1999-2006$ & -0.2 & -0.2 & -0.4 & -0.4 & 1.1 \\
\hline \hline
\end{tabular}

Source: Demographic and Health Surveys; own calculations.

Note: The different country episode formats refer to different clusters with respect to educational levels in the base year, their rate of improvement, and the region. Country episodes marked in bold refer to country episodes that show very low levels in education (net enrolment below $1 / 3$ ) in the base year. Underlined country episodes refer to very large improvements (increase greater than 10 percentage points). Countries in italics refer to countries from SubSaharan Africa (for underlying data, see Table A4).

Thus, these results paint a sobering picture of pro-poor progress in education overall. First, while attendance rates progressed overall in many countries, particularly since 2000, progress in completion rates and years of schooling was much slower. Moreover, progress was often not pro-poor in the strong absolute sense, in particular when it comes to completion rates and years of schooling. In those indicators, progress was particularly anti-poor in country episodes with low initial attendance rates, large improvements in attendance, and in Sub-Saharan Africa.

With the information from Tables 1-3, one can also hone in on individual country experiences. For example, it is interesting that countries which dropped their school fees for primary education in the late 1990s or early 2000s (Ghana, Kenya, Malawi, Tanzania, and Uganda) have not experienced accelerated progress in three educational indicators studied here. Moreover, progress was not particularly pro-poor, compared to other countries in the region. While certainly they helped boost gross enrolment rates at the primary level (e.g., Kattan and Burnett, 2004) these policies have, at least to date, not generated significant pro-poor progress in educational outcomes at higher levels of education. This is most likely related to late entry and slow progression of the poor in the school system as well as high drop-out rates among them ${ }^{18}$.

Figure $4 \mathrm{a}$ and $\mathrm{b}$ rank the 'pro-poorness' of countries for net attendance rates in secondary education and average years of education for the postDakar period ${ }^{19}$ to illustrate which countries have made the strongest propoor progress.

${ }^{18}$ See Orazem et al. (2008), Kattan and Burnett (2004), and King and Orazem (2008) for further discussion of these policies.

${ }^{19}$ And in the case of countries for which only two surveys are available for this particular period. 
Figure 4a - Performance in Pro-Poor Educational Progress (Net Attendance Rate Secondary Education)

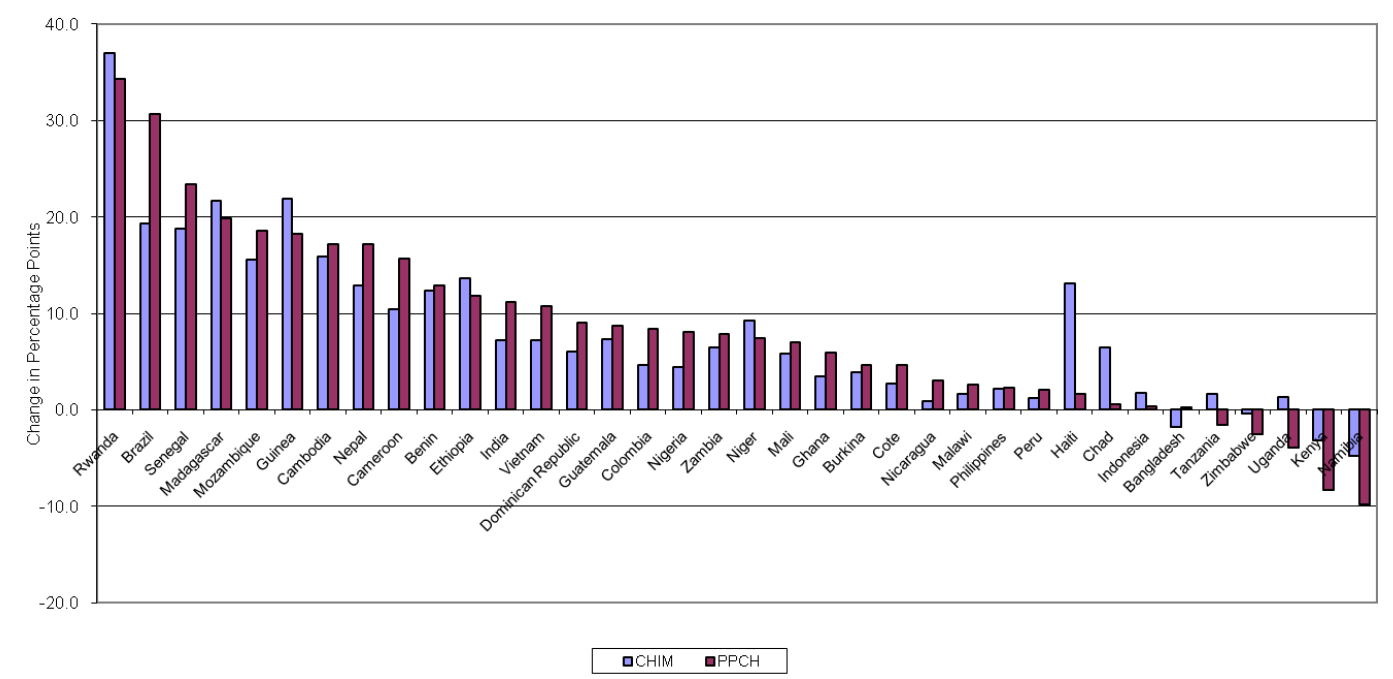

Source: Demographic and Health Surveys (DHS); own calculations.

Figure $4 b$ - Performance in Pro-Poor Educational Progress (Average Years of Education - 17-22)

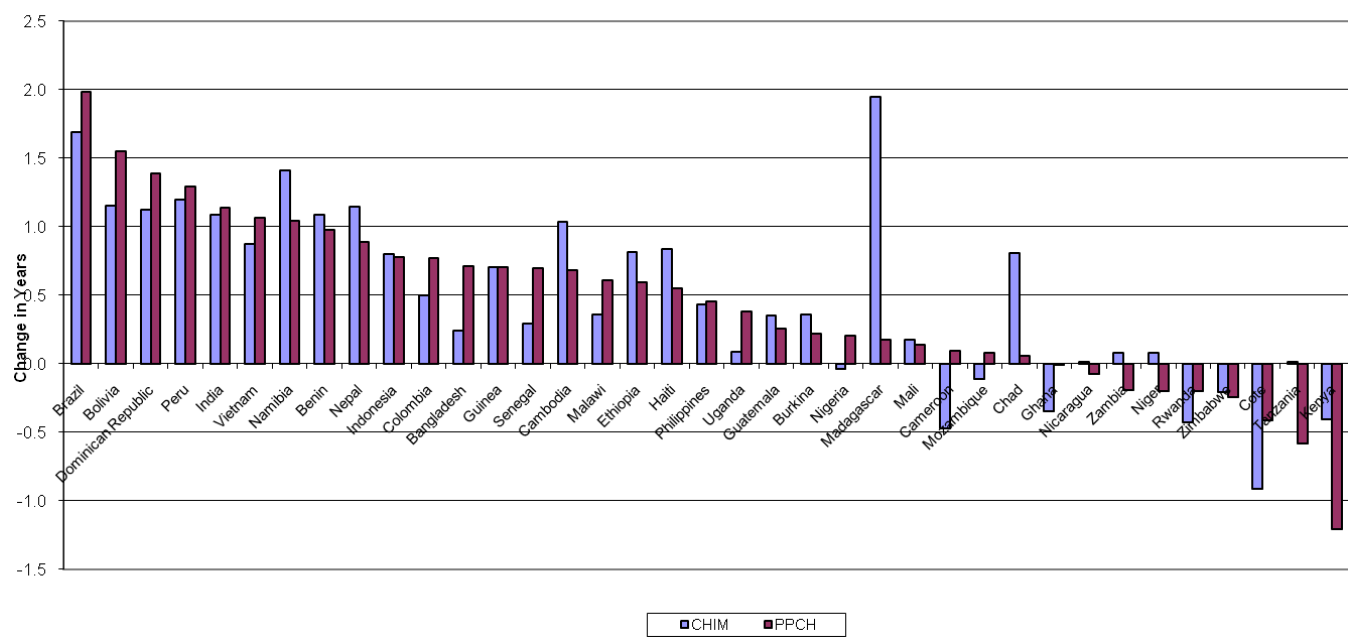

Source: Demographic and Health Surveys (DHS); own calculations.

Countries that have experienced the highest progress in access to education, and where also the PPCH was greater than the CHIM were Brazil, Senegal, Nepal, and Cameroon (Figure 4a). Figure 4b shows the most successful and least successful countries with respect to pro-poor progress in educational outcomes. While again Bolivia, India, Bangladesh, Brazil, and the Dominican Republic dominate the overall pro-poor development, the least successful countries again come from Sub-Saharan Africa. Especially for Madagascar, one clearly sees the large mean progress compared to a very low rate of pro-poor change. These results 
again confirm the foregoing results of great heterogeneity in performance, but also that particularly Sub-Saharan countries did worse in pro-poor progress in educational outcomes.

Figures $5 \mathrm{a}$ and $5 \mathrm{~b}$ provide some additional insights regarding the relationship between pro-poor growth indicators and between initial levels of inequality.

\section{Figure 5a - Correlation of Pro-Poor Progress Indicators}

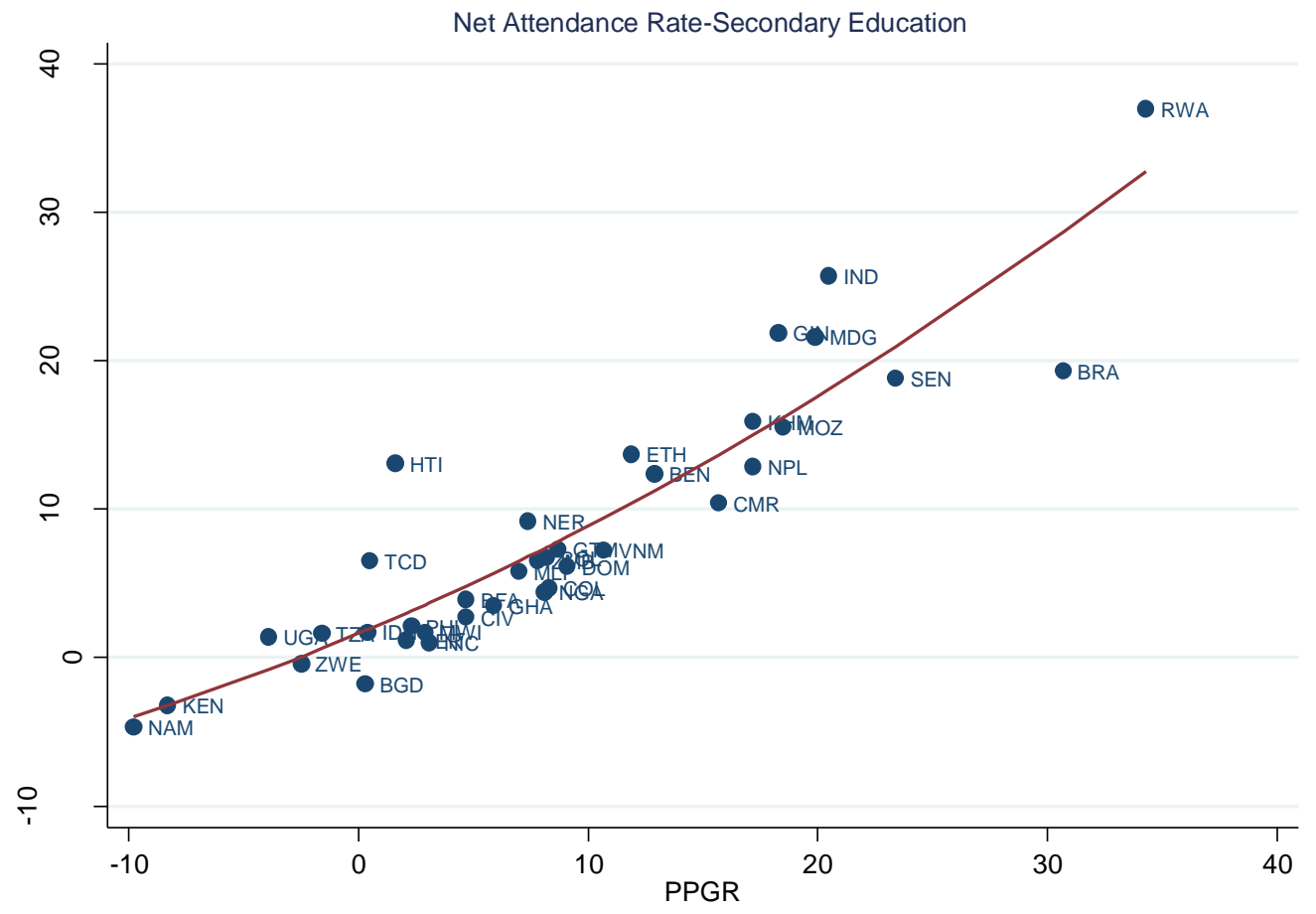

Note: for the Country abbreviations see Table A1 in the Appendix.

Figure 5a shows a very tight relationship between the growth rates in the mean and pro-poor growth rates in secondary attendance. Those below the line showed a higher PPCH than CHIM, thus showing pro-poor progress in the relative sense discussed above. While again there are exceptions in each region, most Asian and Latin American countries are below the line, and Sub-Saharan African countries are found as much above as below the line. 
Figure $5 \mathbf{b}$ - Correlation of Pro-Poor Progress Indicators

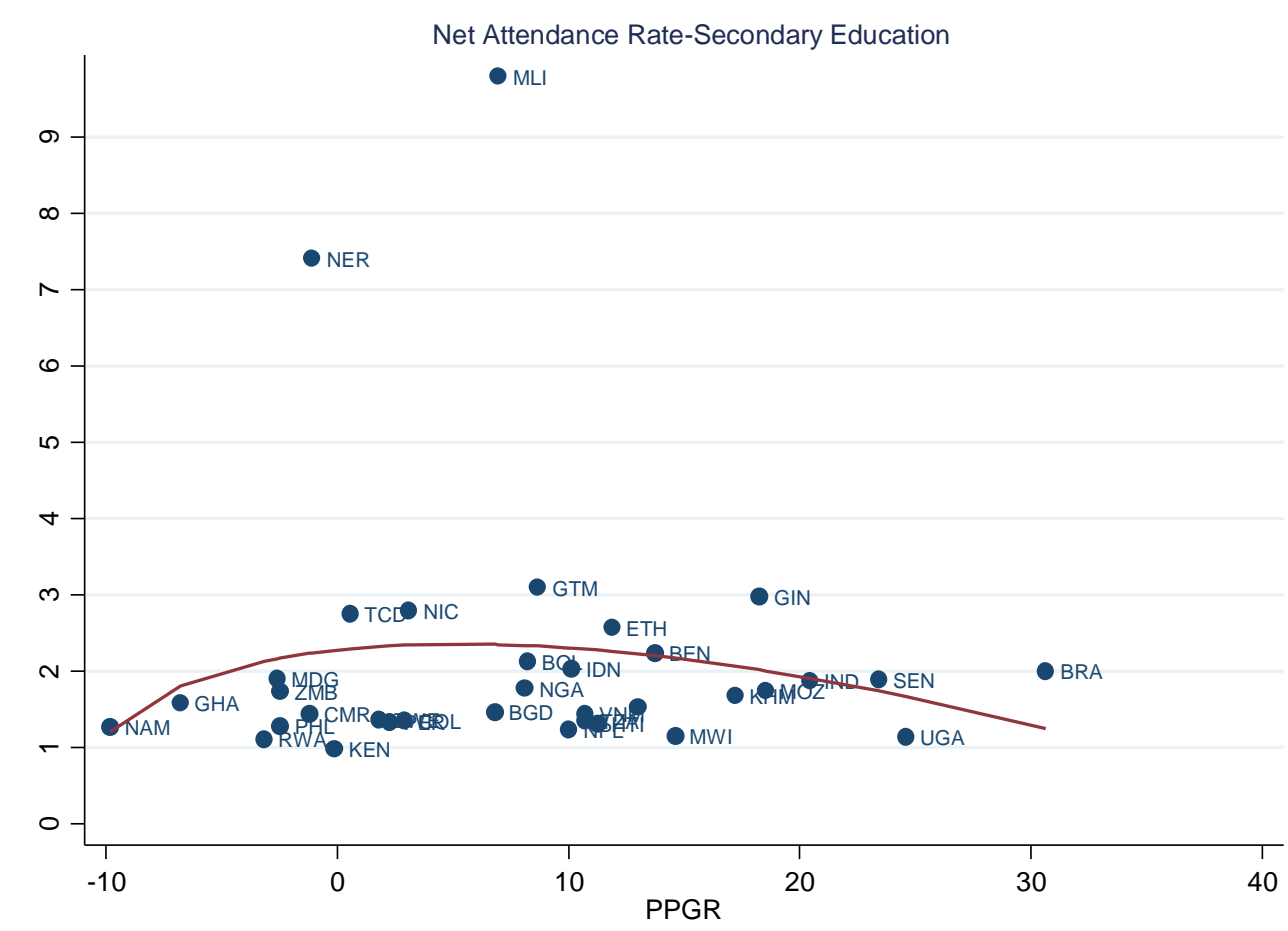

Note: for the Country abbreviations see Table A1 in the Appendix.

Figure $5 \mathrm{~b}$ shows the relationship between the initial level of inequality (the five to one ratio) and the pro-poor growth rates of net attendance rate in secondary education. No clear trend emerges here. In particular, we cannot observe that countries with high initial inequality in education have made the most pro-poor progress; in fact, there are quite a few countries where pro-poor change was very low, despite considerable initial inequality, suggesting that the poor are not catching up, a worrying development.

Concerning the differences in educational inequality between the preDakar and post-Dakar periods, Figures $6 \mathrm{a}$ and $6 \mathrm{~b}$ provide an overview about the differences in the direction and extent of changes in net attendance rate five to one ratio for all countries for which three surveys are available. 
Figure 6a - Differences in Progress in Net Attendance in Secondary Education between the Pre- and Post-Dakar Period*

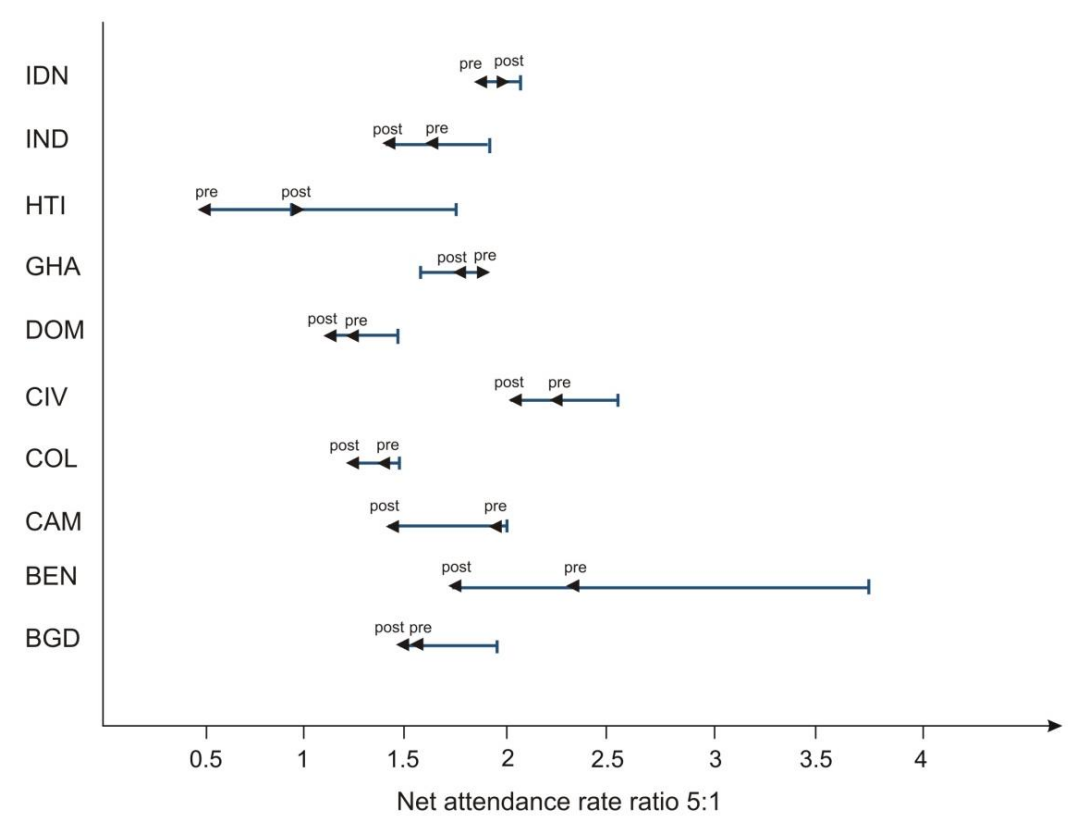

Source: Demographic and Health Surveys (DHS); own calculations.

Figure $\mathbf{6 b}$ - Differences in Progress in Net Attendance in Secondary Education between the Pre- and Post-Dakar Period*

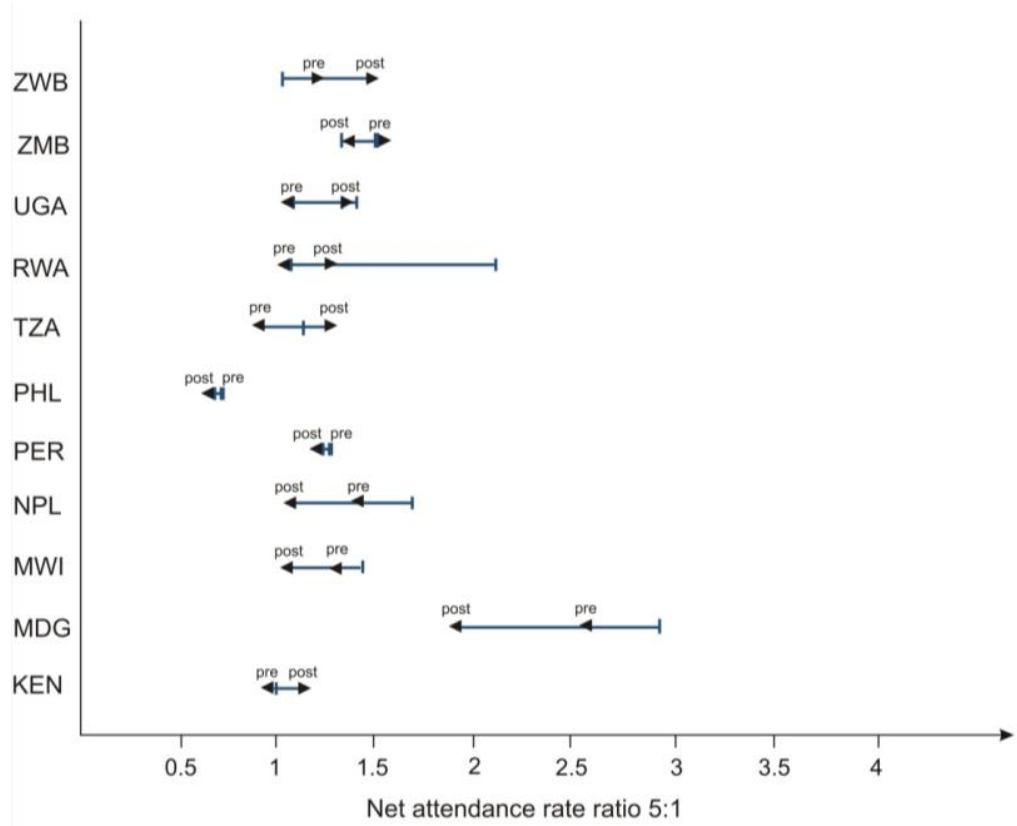

Source: Demographic and Health Surveys (DHS); own calculations.

$\left({ }^{*}\right)$ Burkina Faso and Niger are not included in the Figures as inequality in education is on a different scale in these countries. The respective numbers for Burkina Faso are: 8.45 (base year), 8.42 (pre-Dakar period), 4.88 (post-Dakar period). The respective numbers for Niger are: 7.52 (base year), 8.42 (pre-Dakar period), 4.62 (post-Dakar period). 
In some countries, including Burkina Faso, India, Cambodia, Niger, Malawi, Nepal, and Madagascar, inequality in attendance fell considerably in the post-Dakar period; but in many other countries inequality fell by less, or even increased. This confirms that the commitment to accelerate education in the post-Dakar period has not generally led to a more pro-poor focus.

\subsection{Within-Country Inequalities: Region and Gender}

These national trends just reported on hide important regional and group-specific variation to which we now turn. Of particular relevance are differences by location (rural vs. urban) and by gender. It is beyond the scope of the paper to carefully analyze these trends for each country. Instead we focus on one representative country each to discuss pertinent trends. Table 4 and Figure 7 show the differences in the educational indicators by gender exemplarily for India, a country with high gender gaps (King et al., 2008). For all indicators and periods, two glaring findings emerge. First, the level of access to education and of educational outcomes is considerably higher for boys than for girls. For the richer population groups, the differences are much smaller.

Second, gender specific inequality in education is higher for the poor than for the non-poor. This is illustrated by Figure 7.

\section{Figure 7 - Educational Distribution in India by Gender}
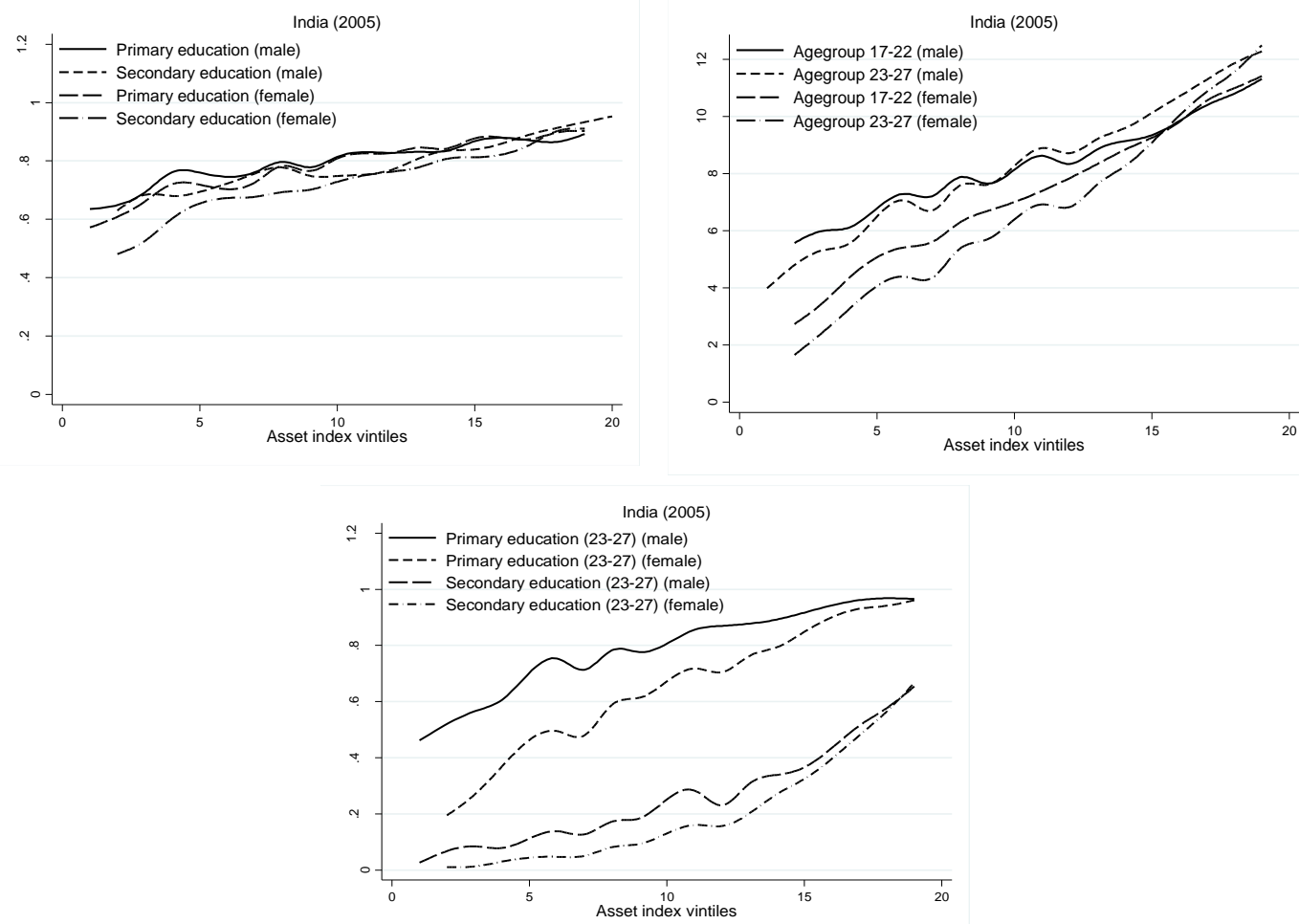

Source: Demographic and Health Surveys (DHS); own calculations. 
Especially when looking at years of education, gender specific inequality in education is first of all a problem for the poor. In richer welfare groups, the one who can afford the costs of education for all children, gender bias in education diminishes considerably. Correspondingly, inequality between welfare groups is higher for girls' education than for boys' education. The five-to-one ratio is significantly higher for girls than for boys for all indicators and periods in India.

Figure 8 shows the absolute non-income growth incidence curve (NIGIC) by gender for India for the two time periods and the three educational indicators.

Figure 8 - Pro-Poor Growth in Education in India by Gender

Net attendance rate
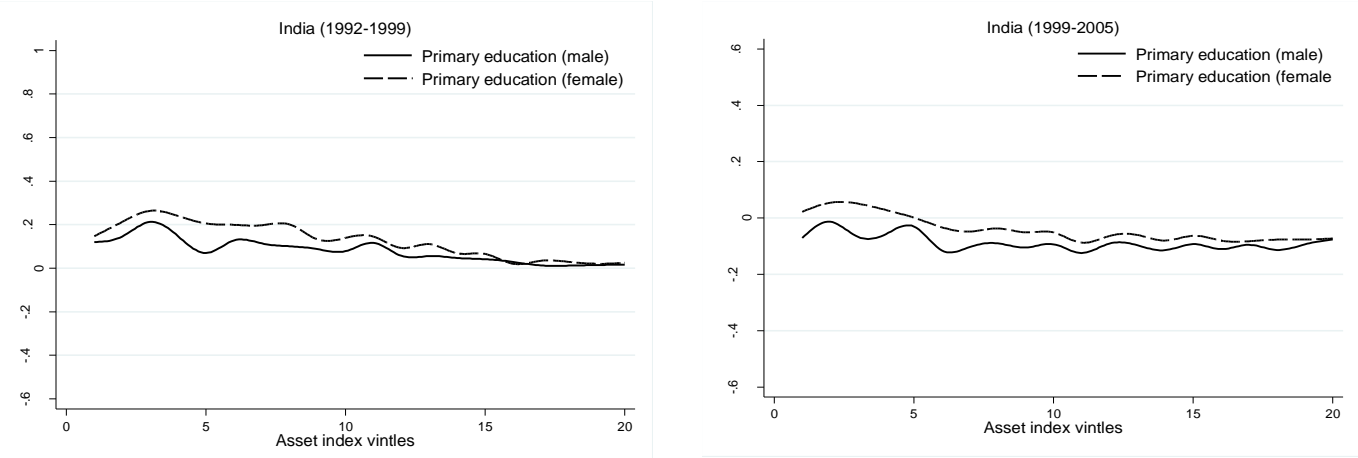

Years of Education
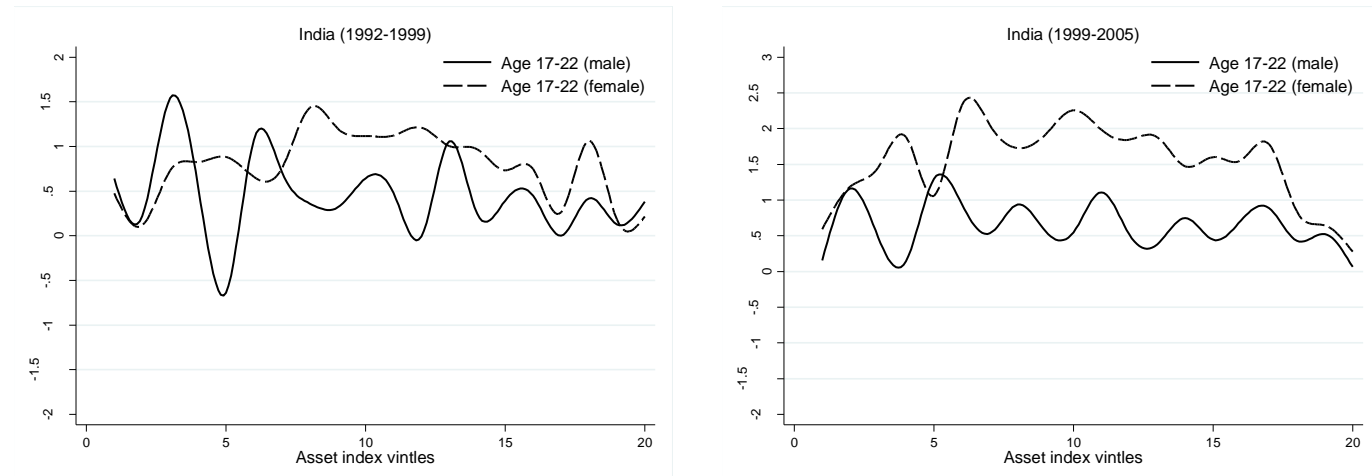
Figure 8- continued
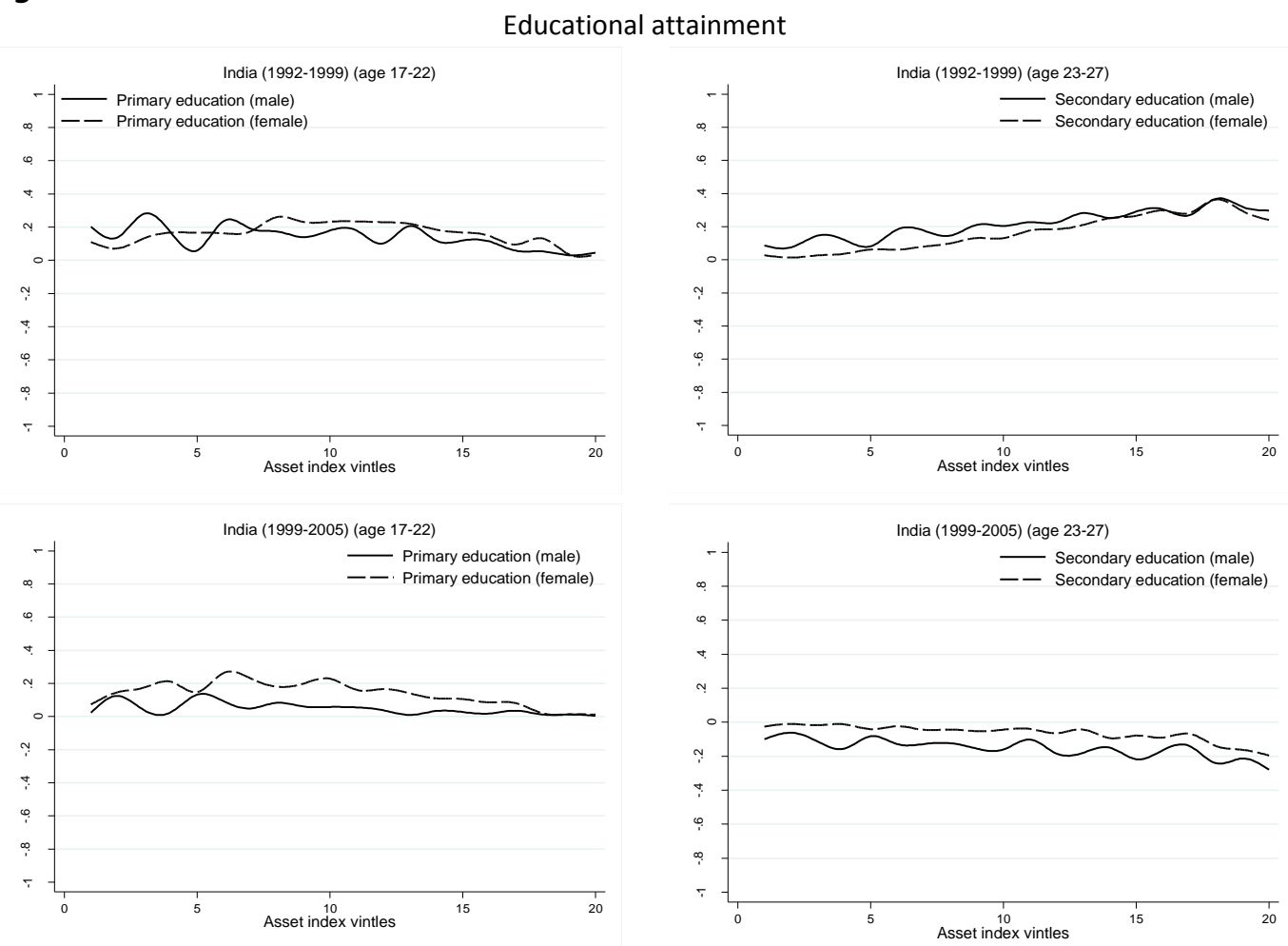

Source: Demographic and Health Surveys (DHS); own calculations.

Overall, we found considerable improvements in access to education and in educational outcomes across the income distribution in India. The NIGICs are essentially flat suggesting that absolute improvements in education were neither favoring the poor nor the non-poor. There is one exception from this overall finding. While the increase in secondary completion was anti-poor in the 1992-1999 period, it was pro-poor in the 1999-2005 period, suggesting that the poor have been able to catch up in more recent years. The second interesting finding concerns gender differentials. Girls seem to have profited more from the expansion of education than boys. This is true in attendance rates, in years of schooling, and in primary and secondary attainment in the later period. It is interesting to note, however, that among the income poor, the improvements for girls and boys were similar. It was among richer groups were girls are catching up; but inequality remains large, so that much more catching up is required (see Table 4). 
Table 4 - Gender Differentials in Education in India

\begin{tabular}{|c|c|c|c|c|c|c|c|c|}
\hline \multirow{2}{*}{ Year } & & \multicolumn{5}{|c|}{ Quintiles } & \multirow{2}{*}{ Mean } & \multirow{2}{*}{ Ratio 5:1 } \\
\hline & & 1 & 2 & 3 & 4 & 5 & & \\
\hline & & & & \multicolumn{3}{|c|}{ Net attendance (primary education) } & & \\
\hline \multirow{2}{*}{1992} & Male & 58.9 & 74.1 & 82.4 & 90.5 & 96.5 & 80.5 & 1.64 \\
\hline & Female & 38.6 & 56.3 & 73.9 & 86.0 & 94.6 & 69.9 & 2.45 \\
\hline \multirow{2}{*}{1999} & Male & 74.6 & 84.3 & 90.9 & 94.9 & 97.9 & 88.5 & 1.31 \\
\hline & Female & 60.2 & 76.4 & 86.7 & 92.8 & 97.3 & 82.7 & 1.62 \\
\hline \multirow{2}{*}{2005} & Male & 69.2 & 76.0 & 80.6 & 84.5 & 88.5 & 79.7 & 1.28 \\
\hline & Female & 63.9 & 73.4 & 80.5 & 85.7 & 89.6 & 78.6 & 1.40 \\
\hline \multicolumn{9}{|c|}{ Net attendance (secondary education) } \\
\hline \multirow{2}{*}{1992} & Male & 37.5 & 44.6 & 49.8 & 51.3 & 55.3 & 47.7 & 1.48 \\
\hline & Female & 18.1 & 28.4 & 38.6 & 46.9 & 52.9 & 37.0 & 2.92 \\
\hline \multirow{2}{*}{1999} & Male & 59.9 & 67.4 & 74.3 & 81.8 & 90.3 & 74.7 & 1.51 \\
\hline & Female & 34.8 & 48.6 & 61.9 & 73.9 & 87.5 & 61.3 & 2.52 \\
\hline \multirow{2}{*}{2005} & Male & 65.1 & 74.5 & 77.0 & 83.6 & 91.9 & 78.4 & 1.41 \\
\hline & Female & 51.4 & 65.1 & 74.3 & 81.3 & 89.6 & 72.3 & 1.74 \\
\hline \multicolumn{9}{|c|}{ Average years of education (age group 17-22) } \\
\hline \multirow{2}{*}{1992} & Male & 4.4 & 5.9 & 7.1 & 8.2 & 10.3 & 7.2 & 2.32 \\
\hline & Female & 1.4 & 2.6 & 4.2 & 6.6 & 9.8 & 4.9 & 6.83 \\
\hline \multirow{2}{*}{1999} & Male & 5.2 & 6.3 & 7.5 & 8.7 & 10.5 & 7.6 & 2.03 \\
\hline & Female & 2.0 & 3.6 & 5.4 & 7.4 & 10.3 & 5.7 & 5.16 \\
\hline \multirow{2}{*}{2005} & Male & 5.6 & 7.2 & 8.2 & 9.3 & 11.0 & 8.3 & 1.95 \\
\hline & Female & 3.3 & 5.4 & 7.4 & 9.0 & 11.2 & 7.2 & 3.40 \\
\hline \multicolumn{9}{|c|}{ Primary education completion (age group 17-22) } \\
\hline \multirow{2}{*}{1992} & Male & 38.3 & 53.1 & 65.0 & 75.1 & 90.7 & 64.4 & 2.37 \\
\hline & Female & 10.9 & 21.7 & 36.9 & 59.6 & 85.1 & 42.8 & 7.81 \\
\hline \multirow{2}{*}{1999} & Male & 58.2 & 69.7 & 79.8 & 88.9 & 95.4 & 78.4 & 1.64 \\
\hline & Female & 23.1 & 40.9 & 60.0 & 77.3 & 92.6 & 58.8 & 4.01 \\
\hline \multirow{2}{*}{2005} & Male & 63.2 & 78.5 & 85.1 & 91.1 & 97.1 & 83.0 & 1.54 \\
\hline & Female & 38.4 & 61.4 & 78.8 & 88.5 & 95.9 & 72.6 & 2.50 \\
\hline \multicolumn{9}{|c|}{ Secondary education completion (age group 17-22) } \\
\hline \multirow{2}{*}{1992} & Male & 5.5 & 8.3 & 11.2 & 16.9 & 38.1 & 16.0 & 6.86 \\
\hline & Female & 1.3 & 2.4 & 4.2 & 10.7 & 37.7 & 11.2 & 29.89 \\
\hline \multirow{2}{*}{1999} & Male & 16.4 & 23.0 & 32.9 & 45.1 & 69.7 & 37.4 & 4.25 \\
\hline & Female & 3.9 & 10.0 & 19.8 & 36.1 & 67.2 & 27.4 & 17.24 \\
\hline & Male & 5.4 & 11.3 & 17.8 & 27.2 & 48.1 & 22.0 & 8.92 \\
\hline 2005 & Female & 2.2 & 6.2 & 14.7 & 28.5 & 53.3 & 21.0 & 23.81 \\
\hline & & & High & ucatio & npletio & e grou & -22) & \\
\hline 1992 & Male & 2.4 & 3.3 & 4.7 & 7.6 & 19.8 & 7.6 & 8.36 \\
\hline 1992 & Female & 0.8 & 1.1 & 1.5 & 4.6 & 21.4 & 5.9 & 28.47 \\
\hline & Male & 8.3 & 12.2 & 18.5 & 29.0 & 52.3 & 24.1 & 6.28 \\
\hline 1999 & Female & 1.4 & 4.4 & 9.4 & 21.5 & 51.3 & 17.6 & 37.13 \\
\hline 2005 & Male & 2.0 & 4.2 & 8.1 & 13.3 & 26.7 & 10.9 & 13.57 \\
\hline$<005$ & Female & 0.9 & 2.3 & 6.0 & 13.1 & 32.1 & 10.9 & 34.38 \\
\hline
\end{tabular}

Source: Demographic and Health Surveys (DHS); own calculations.

However, overall, we find that gender differences in education remain persistent for countries with low overall attendance rates. Besides the positive development in India, under participation in education of girls is a persisting concern in Sub-Saharan African countries. This regions show no real progress in achieving gender parity. 
Table 5 and Figure 9 show the differences in access to education and in educational outcomes between rural and urban areas in Burkina Faso, which mirrors the overall trend across the countries in the sample.

Table 5 - Regional Differentials in Education in Burkina Faso

\begin{tabular}{|c|c|c|c|c|c|c|c|c|}
\hline \multirow{2}{*}{ Year } & \multirow{2}{*}{ Region } & \multicolumn{5}{|c|}{ Quintiles } & \multirow{2}{*}{ Mean } & \multirow{2}{*}{$\begin{array}{r}\text { Ratio } \\
5: 1\end{array}$} \\
\hline & & 1 & 2 & 3 & 4 & 5 & & \\
\hline \multicolumn{9}{|c|}{ Net attendance (primary education) } \\
\hline \multirow{2}{*}{1992} & Urban & 57.4 & 65.9 & 77.3 & 77.0 & 89.3 & 73.4 & 1.55 \\
\hline & Rural & 13.3 & 15.3 & 19.5 & 24.7 & 41.5 & 22.9 & 3.12 \\
\hline \multirow{2}{*}{1998} & Urban & 61.9 & 74.2 & 74.1 & 88.0 & 84.8 & 76.6 & 1.37 \\
\hline & Rural & 13.6 & 17.0 & 21.0 & 24.4 & 31.2 & 21.4 & 2.29 \\
\hline \multirow{2}{*}{2003} & Urban & 56.7 & 69.8 & 77.3 & 84.4 & 86.0 & 74.8 & 1.52 \\
\hline & Rural & 17.3 & 19.3 & 23.9 & 27.7 & 36.9 & 25.0 & 2.14 \\
\hline \multicolumn{9}{|c|}{ Net attendance (secondary education) } \\
\hline \multirow{2}{*}{1992} & Urban & 30.6 & 41.6 & 47.5 & 45.5 & 59.2 & 44.9 & 1.94 \\
\hline & Rural & 5.6 & 6.4 & 6.4 & 8.2 & 20.2 & 9.4 & 3.64 \\
\hline \multirow{2}{*}{1998} & Urban & 32.2 & 40.5 & 41.8 & 54.3 & 60.2 & 45.8 & 1.87 \\
\hline & Rural & 5.4 & 4.6 & 7.0 & 9.0 & 14.7 & 8.2 & 2.72 \\
\hline \multirow{2}{*}{2003} & Urban & 35.5 & 41.3 & 44.2 & 55.9 & 58.1 & 47.0 & 1.64 \\
\hline & Rural & 8.8 & 10.7 & 12.2 & 15.1 & 19.7 & 13.3 & 2.25 \\
\hline \multicolumn{9}{|c|}{ Average years of education (age group 17-22) } \\
\hline \multirow{2}{*}{1992} & Urban & 3.2 & 4.6 & 4.5 & 5.4 & 6.9 & 4.9 & 2.20 \\
\hline & Rural & 0.5 & 0.3 & 0.6 & 1.0 & 2.0 & 0.9 & 4.31 \\
\hline \multirow{2}{*}{1998} & Urban & 3.6 & 5.0 & 5.4 & 6.0 & 6.7 & 5.3 & 1.87 \\
\hline & Rural & 0.5 & 0.5 & 0.6 & 0.8 & 1.4 & 0.8 & 2.55 \\
\hline \multirow{2}{*}{2003} & Urban & 3.8 & 4.6 & 5.5 & 6.6 & 7.0 & 5.5 & 1.83 \\
\hline & Rural & 0.6 & 0.9 & 1.2 & 1.4 & 2.2 & 1.2 & 3.49 \\
\hline \multicolumn{9}{|c|}{ Primary education completion (age group 17-22) } \\
\hline \multirow{2}{*}{1992} & Urban & 34.7 & 47.4 & 48.5 & 55.7 & 71.1 & 51.5 & 2.05 \\
\hline & Rural & 5.0 & 3.0 & 7.8 & 10.6 & 23.7 & 10.0 & 4.78 \\
\hline \multirow{2}{*}{1998} & Urban & 37.1 & 54.6 & 59.5 & 58.7 & 69.5 & 55.9 & 1.87 \\
\hline & Rural & 5.1 & 4.8 & 7.2 & 9.8 & 15.2 & 8.4 & 2.97 \\
\hline \multirow{2}{*}{2003} & Urban & 39.4 & 46.5 & 56.9 & 67.6 & 70.9 & 56.2 & 1.80 \\
\hline & Rural & 5.6 & 8.4 & 12.4 & 13.0 & 24.2 & 12.7 & 4.30 \\
\hline \multicolumn{9}{|c|}{ Secondary education completion (age group 17-22) } \\
\hline \multirow{2}{*}{1992} & Urban & 0.9 & 3.3 & 2.8 & 4.8 & 7.9 & 3.9 & 8.77 \\
\hline & Rural & 0.0 & 0.3 & 1.2 & 0.3 & 0.7 & 0.5 & n.d. \\
\hline & Urban & 4.6 & 2.3 & 3.2 & 2.9 & 5.0 & 3.6 & 1.10 \\
\hline 1998 & Rural & 0.5 & 0.0 & 0.4 & 0.4 & 0.6 & 0.4 & 1.26 \\
\hline 2003 & Urban & 1.7 & 1.9 & 3.4 & 5.4 & 8.7 & 4.2 & 5.26 \\
\hline 2003 & Rural & 0.0 & 0.0 & 0.0 & 0.3 & 0.8 & 0.2 & n.d. \\
\hline & & -ligher & ation & letion & group & & & \\
\hline & Urban & 0.9 & 1.4 & 0.8 & 2.5 & 4.7 & 2.1 & 5.21 \\
\hline 1992 & Rural & 0.0 & 0.3 & 1.2 & 0.3 & 0.7 & 0.5 & n.d. \\
\hline 1998 & Urban & 3.4 & 0.9 & 0.0 & 1.4 & 1.5 & 1.5 & 0.45 \\
\hline 1998 & Rural & 0.5 & 0.0 & 0.4 & 0.2 & 0.6 & 0.3 & 1.26 \\
\hline 2003 & Urban & 0.0 & 0.0 & 0.2 & 0.7 & 3.0 & 0.9 & n.d. \\
\hline 2003 & Rural & 0.0 & 0.0 & 0.0 & 0.0 & 0.5 & 0.1 & n.d. \\
\hline
\end{tabular}

Source: Demographic and Health Surveys (DHS); own calculations.

As expected, access to education and educational outcomes are much higher in urban areas than in rural areas. This is illustrated in Figure 9 for the year 2003. Although the curves show a similar pattern across the 
distribution, one can see the large difference in the level of access to education between rural and urban areas.

\section{Figure 9 - Educational Distribution in Burkina Faso by Region}
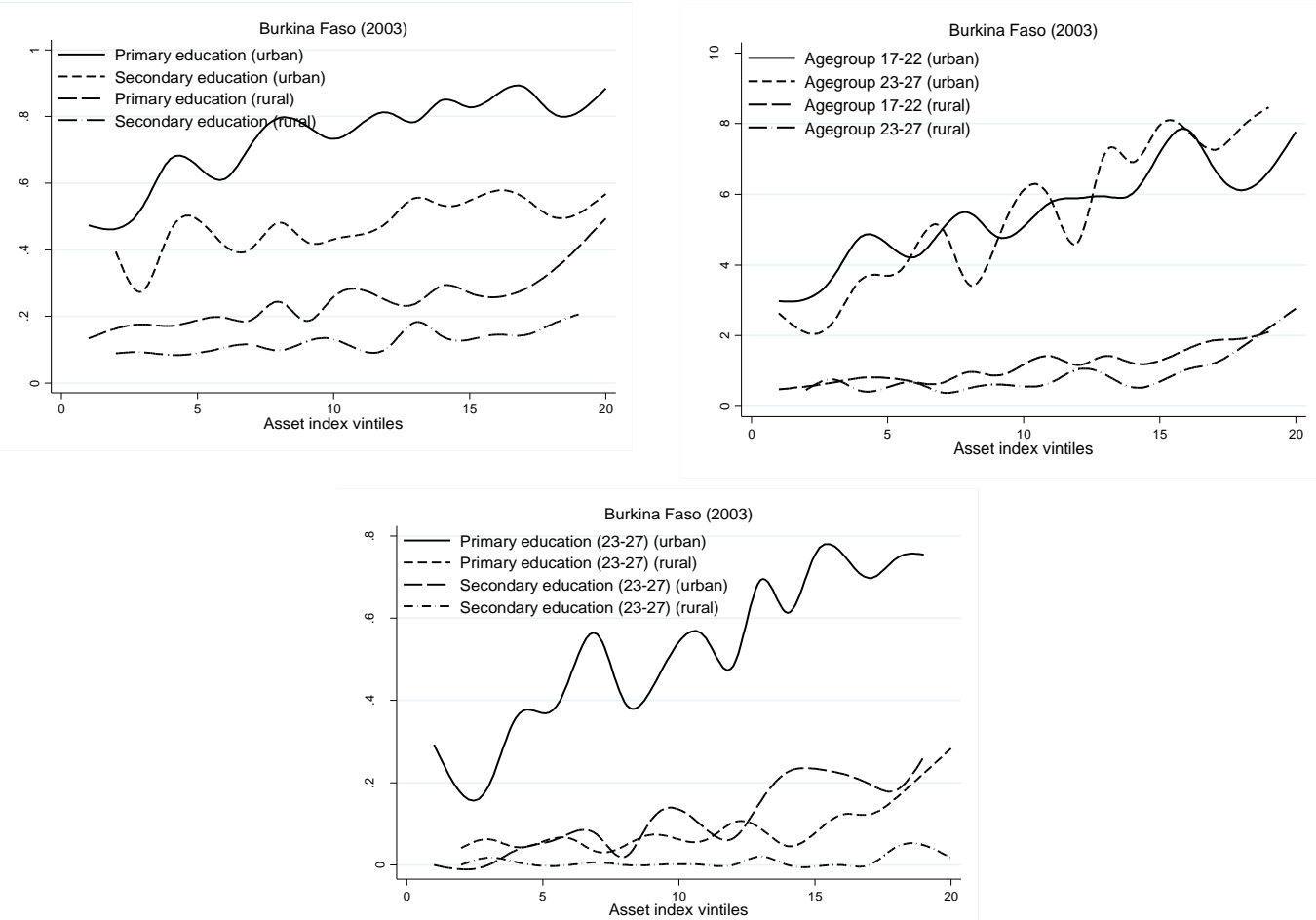

Source: Demographic and Health Surveys (DHS); own calculations.

Looking at the difference between urban and rural areas across the welfare distribution, two main findings emerge. First, inequality in education is higher in rural areas than in urban areas. For example, whereas the five to one ratio for primary education completion in 2003 is 1.799 in urban areas, it was 4.299 in rural areas. Second, differences in education between urban and rural areas are higher for the poor than for the non-poor. For example, the urban rural ratio in years of education in 2003 was 7 for the poorest asset index quintile, for the richest quintile it was 2.9 .

Figure 10 shows the pro-poor progress in education in Burkina Faso by urban and rural areas. 
Figure 10 - Pro-Poor Growth in Education in Burkina Faso by Region

Net attendance rate
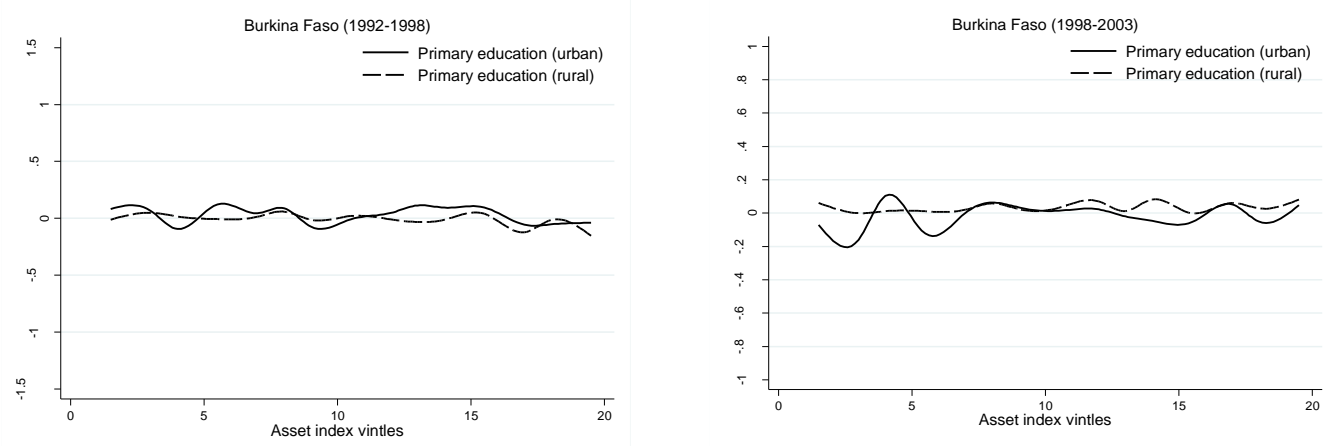

Years of education
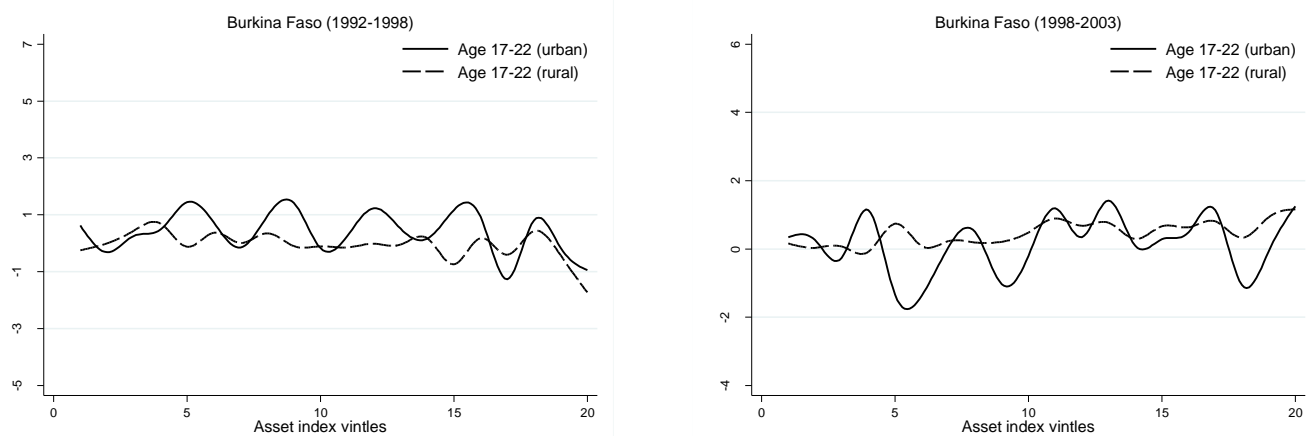

Educational attainment
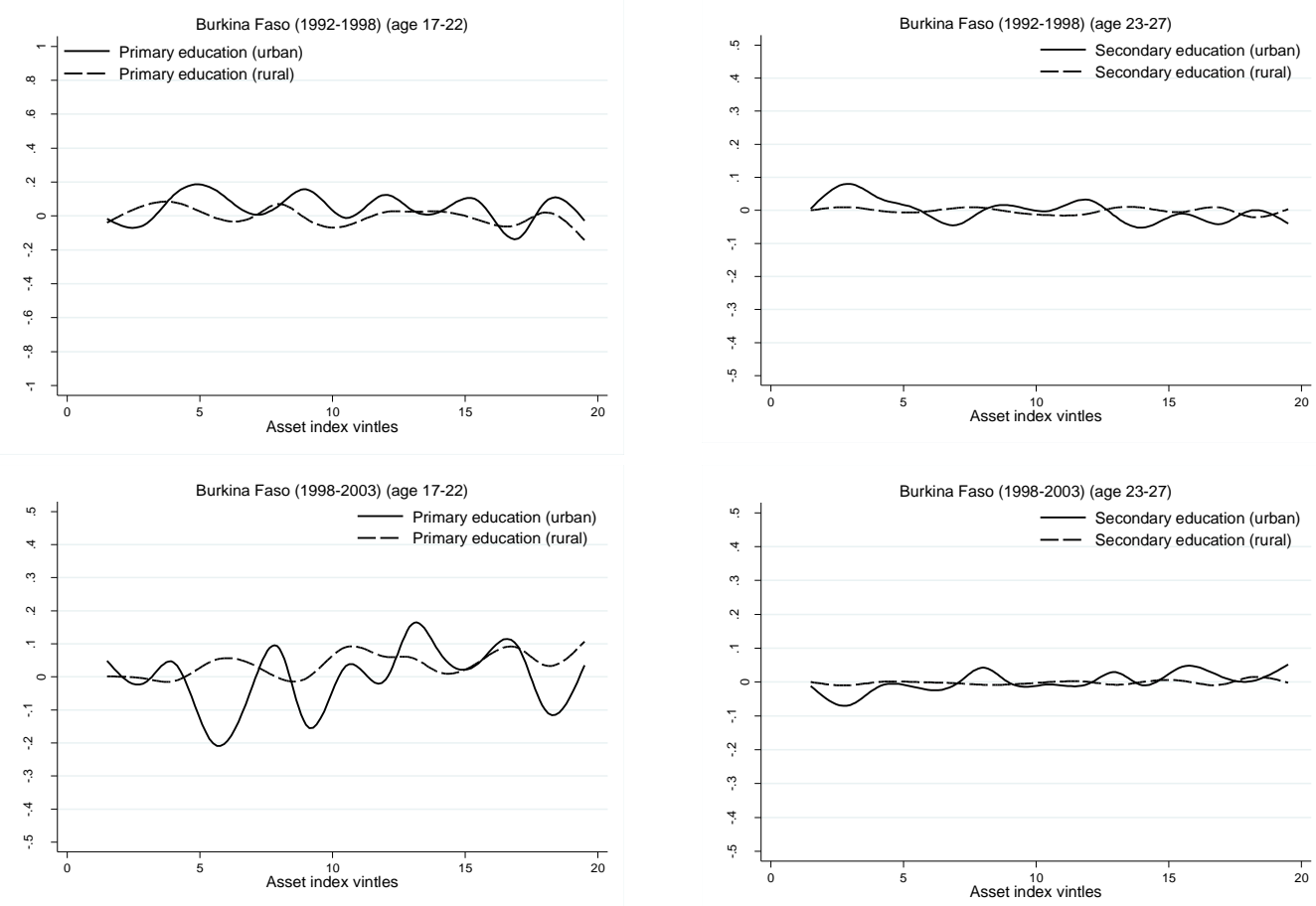

Source: Demographic and Health Surveys (DHS); own calculations. 
Besides an overall increase in the access to education and also in educational outcomes, sub-national disparities remain between urban and rural areas in both periods. For both periods, the curves are essentially flat among the income distribution, and there are no differences between educational growth in urban and rural areas. Thus, here the message is more negative in the sense that there is not even a tendency for the large urban-rural differences to decline in Burkina Faso, as in many similar African countries with relatively low educational attainment rates.

\section{Concluding Remarks}

The question whether the poor can benefit from progress in access to the education system and educational outcomes is of considerable importance with respect the achievements of the EFA goals until 2015. The aim of the paper was to identify and understand which parts of the population have benefited from the improvements in the access to the education system and in educational outcomes and to highlight the differences in the progress, if any, between the pre- and post-Dakar periods.

Concerning within-country differences in education by welfare our results point to very significant inequalities in education within most countries. Richer population subgroups have better access to education and higher educational outcomes than poorer population subgroups. Within country inequality in access to education exhibits a similar pattern to between country inequality. While inequality in attendance falls with rising average attendance, inequality in achievement rises with average achievements. This suggests that reducing inequality in attendance is not sufficient to (eventually) reduce inequality in achievements, as drop-outs and poor progress within the educational system ensures that inequalities in achievements remain sizable.

Concerning pro-poor progress in education, we find great country heterogeneity. While some countries have shown pro-poor progress in all educational indicators, in others educational progress was clearly antipoor, or there was no progress at all using our indicators. There is tendency for progress to be more pro-poor in countries with higher initial levels of attendance and with lower overall improvements in attendance. A more solid finding is that educational progress was generally higher and more pro-poor in Asia and Latin America than in Africa.

The inability to explain much of this heterogeneity points to the need to scrutinize educational policy and specific country conditions more carefully than was possible in this overview paper that examines trends in 37 countries. One of the good news of our results is that the heterogeneity 
in trends suggests that pro-poor educational progress appears to be possible in many different settings so that policy seems to be able to influence the pattern of progress in education; it also suggests that high inequalities are not inevitable and can be tackled. The one policy we examined, free primary schooling, did not lead to markedly higher overall, or more pro-poor, attendance or completion rates at the secondary levels.

Concerning gender specific and region specific differences in education within countries we find that, first, the level of access to education and of educational outcomes are considerably higher for boys than for girls and higher in urban than in rural areas. Second, gender specific and region specific inequality in education is higher for the poor than for the nonpoor. Third, we find that girls have benefited more from the expansion of education than boys in India (and many other places) while there are no discernible differences between educational progress between rural and urban areas, particularly in Africa.

It is important to conclude with four methodological caveats. First, by focusing on net attendance rates, many important aspects of educational dynamics are not fully captured. In particular, it may be the case that in many African countries educational progress is much higher in terms of older children returning to school or going to school for the first time, also as a result of user fees being lifted. As many of these children are not in the appropriate age range for the level of schooling, they will not be considered in net attendance rates. Second, the timing of the survey can have an impact of (slightly) biasing the results of trends in net attendance rates. Take the extreme case where a first survey was undertaken in September, at the beginning of the new school year, while the second one in July, at the end of the school year. If the surveys are 5 years apart, most children will have aged by 5 years in the survey (except those with birthdays in August); but all will only have progressed 4 grades in the school system. In such a situation, progress in education will appear lower than in another one where the same survey was done in September. This is an issue which affects a few countries (e.g., India between 1999 and 2004 where the first survey took place in December and the second in January thereby understating educational progress) and would need attention in further studies. Third, one should bear in mind that we are working with samples here and thus statistical significance of results will be an issue, both for the division of households into asset groups as well as the measurement of progress (see Grosse et al., 2008, for more details). Lastly, one should point out that the results here on attendance will not necessarily coincide with administrative data on enrolments which are extensively used by UNESCO. While the administrative data might have advantages in terms of accuracy in system with high quality 
administrative stuctures, they measure initial enrolment and not regular attendance which might be the more relevant indicator. 


\section{References}

Alderman, H., Kim, J., \& Orazem, P.F. (2003). Design, Evaluation, and Sustainability of Private Schools for the Poor: the Pakistan Urban and Rural Fellowship School Experiments. Economics of Education Review, 22 (3), 265-274. doi:10.1016/S0272-7757(02)00051-1

Berthélemy, J.C. (2005). To what Extent are African Education Policies ProPoor? Journal of African Economies, 15 (3), 434-469. doi:10.1093/jae/eji032

Chabbott, C., \& Ramirez, F.O. (2000). Development and Education. In M. Hallinan (ed.), Handbook of the Sociology of Education, New York: Kluwer Academic.

De, A., \& Dreze, J. (1999). Public Report on Basic Education in India. New Delhi: Oxford University Press.

Duclos, J.Y., \& Wodon, Q. (2004). What is 'Pro-Poor'? Mimeographed. World Bank, Washington, D.C.

Duflo, E. \& L. Breierova (2004). The Impact of Education on Fertility and Child Mortality: Do Fathers Really Matter less than Mothers? NBER Working Paper, 10513.

Duflo, E. (2001). Schooling and Labor Market Consequences of School Construction in Indonesia: Evidence from an Unusual Policy Experiment. American Economic Review, 91 (4), 795-813.

Filmer, D. (2004). If You Build It, Will They Come? School Availability and School Enrollment in 21 Poor Countries. World Bank Policy Research Paper, 3340.

Filmer, D., \& Pritchett, L.H. (2001). Estimating Wealth Effects without Expenditure Data - or Tears: an Application to Educational Enrollments in States of India. Demography, 38 (1), 115-132.

Glewwe, P., Jacoby, H.G., \& King, E. M. (2001). Early Childhood Nutrition and Academic Achievement: a Longitudinal Analysis. Journal of Public Economics, 81 (3), 345-368. doi:10.1016/S0047-2727(00)00118-3

Grimm, M. (2007). Removing the Anonymity Axiom in Assessing ProPoor Growth. With an Application to Indonesia and Peru. Journal of Economic Inequality, 5 (2), 179-197. doi:10.1007/s10888-006-9038-4

Grosse, M., Harttgen, K., \& Klasen, S. (2008). Measuring Pro-Poor Growth using Non-Income Dimensions. World Development, 36 (6), 1021-1047. doi:10.1016/j.worlddev.2007.10.009

Kakwani, N., \& Son, H. H. (2008). Poverty Equivalent Growth Rate. Review of Income and Wealth, 54 (4), 643-655. doi:10.1111/j.1475-4991.2008.00293.x 
Kattan, R., \& Burnett, N. (2004). User Fees in Primary Education. Mimeographed, Washington DC: The World Bank.

King, E.M., Klasen, S., \& Porter, M. (2008), Women and Development. Copenhagen Consensus 2008 Perspective Paper, Copenhagen Consensus Center.

King, E.M., \& Orazem, P.F. (2008). Schooling in Developing Countries: The Roles of Supply, Demand and Government Policy. Handbook of Development Economics, Volume 4, Elsevier.

Klasen, S. (2008). Economic Growth and Poverty Reduction: Measurement Issues in Income and Non-Income Dimensions. World Development, 36 (3), 420-445. doi:10.1016/j.worlddev.2007.03.008

Lanjouw, P. \& Ravallion, M. (1998). Benefit Incidence and the Timing of Program Capture. Washington: World Bank.

LeVine, R.A., LeVine, S.E., Rowe, M.L., \& Schnell-Anzola, B. (2004). Maternal Literacy and Health Behavior: a Nepalese Case Study. Social Science and Medicine, 58 (4), 866-877. doi:10.1016/S0277-9536(03)00261-2

Miguel, E., \& Kremer, M. (2004). Worms: Identifying Impacts on Education and Health in the Presence of Treatment Externalities. Econometrica, 72 (1), 159-217. doi:10.1111/j.1468-0262.2004.00481.x

Milligan, K., Moretti, E., \& Oreopoulos, P. (2003)., Does Education Improve Citizenship? Evidence from the US and the UK. Journal of Public Economics, 88 (9), 1667-1695. doi:10.1016/j.jpubeco.2003.10.005

OECD (2001). Rising to the Global Challenge: Partnership for Reducing World Poverty. Statement by the DAC High Level Meeting. April 25- 26, 2001, Paris: OECD.

OECD (2006). Promoting Pro-Poor Growth: Key Policy Messages. Paris. OECD.

Orazem, P.F., Glewwe, P., \& Patrinos, H. (2008). Education. Copenhagen Consensus 2008 Challenge Paper. Copenhagen Consensus Center.

Pritchett, L. (2004). Access to Education. In Lomborg, B., (ed.) Global Crises, Global Solutions. Cambridge: Cambridge University Press. doi:10.1017/CBO9780511492624.005

Ravallion, M., \& Chen, S. (2003). Measuring Pro-Poor Growth. Economics Letters, 78 (1), 93-99. doi:10.1016/S0165-1765(02)00205-7

Roberts, J. (2003). Poverty Reduction Outcomes in Education and Health: Public Expenditure and Aid. Overseas Development Institute Working Paper, 210.

Sahn, D.E., \& Stifel, D. (2003). Exploring Alternative Measures of Welfare in the Absence of Expenditure Data. Review of Income and Wealth, 49 (4), 463-489. doi:10.1111/j.0034-6586.2003.00100.x 
Schultz, P.T. (2002). Why Governments Should Invest More to Educate Girls. World Development, 30 (2), 207-225. doi:10.1016/S0305750X(01)00107-3

Sen, A.K. (1988). The Concept of Development. In Chenery, H., \& Srinivasan, T., (eds.), Handbook of Development Economics, Volume 1, Elsevier.

Smits, J., Huisman, J., \& Webbink, E. (2007). Family Background, District and National Determinants of Primary School Enrollment in 62 Developing Countries. Paper presented at the XIII World Congress of Comparative Education Societies, Sarajevo, 3-7 September.

Son, H. (2003). Approaches to Defining and Measuring Pro-Poor Growth. Mimeo, Washington: World Bank.

UN (2000). A Better World for All. New York: United Nations.

UNESCO (2008). Education for All by 2015 - Will we Make it? EFA Global Monitoring Report 2008. Paris:UNESCO.

Van de Walle, D. (1998). Assessing the Welfare Impacts of Public Spending. World Development, 26 (3), 365-379. doi:10.1016/S0305750X(97)10064-X

Van de Walle, D., \& Nead, K. (eds.) (1995). Public Spending and the Poor Theory and Evidence. Published for the World Bank, Baltimore and London: John Hopkins University Press.

World Bank (2007). World Development Indicators. World Bank.

Wößmann, L. (2003). Schooling Resources, Educational Institutions, and Student Performance: The International Evidence. Oxford Bulletin of Economics and Statistics, 65 (2), 117-170. doi:10.1111/1468-0084.00045 


\section{Appendix}

Table A1 - Demographic and Health Surveys by Country and Years

\begin{tabular}{llll}
\hline \hline Country & Years & Country & Years \\
\hline Bangladesh (BGD) & $1993,1999,2004$ & Tanzania (TZA) & $1992,1996,2004$ \\
\hline Benin (BEN) & $1996,2001,2006$ & Rwanda (RWA) & $1992,2000,2005$ \\
\hline Bolivia (BOL) & $1994,1998,2003$ & Uganda (UGA) & $1995,2000,2006$ \\
\hline Burkina Faso (BFA) & $1992,1998,2003$ & Zambia (ZMB) & $1992,1996,2001$ \\
\hline Cameroon (CMR) & $1991,1998,2004$ & Zimbabwe (ZWE) & $1994,1999,2006$ \\
\hline Colombia (COL) & $1995,2000,2005$ & & \\
\hline Cote d'Ivoire (CIV) & $1994,1999,2004$ & Brazil (BRA) & 1991,1996 \\
\hline Dominican Republic (DOM) & $1991,1996,2002$ & Cambodia (KHM) & 2000,2005 \\
\hline Ghana (GHA) & $1993,1998,2003$ & Chad (TCD) & 1996,2004 \\
\hline Haiti (HTI) & $1994,2000,2005$ & Ethiopia (ETH) & 1998,2005 \\
\hline India (IND) & $1992,1999,2005$ & Guatemala (GTM) & 1995,1999 \\
\hline Indonesia (IDN) & $1991,1997,2003$ & Guinea (GIN) & 1999,2005 \\
\hline Kenya (KEN) & $1993,1998,2003$ & Mali (MLI) & 1996,2001 \\
\hline Madagascar (MDG) & $1992,1997,2004$ & Mozambique (MOZ) & 1997,2003 \\
\hline Malawi (MWI) & $1992,2000,2004$ & Namibia (NAM) & 1992,2000 \\
\hline Nepal NPL) & $1996,2001,2006$ & Nicaragua (NIC) & 1997,2001 \\
\hline Niger (NER) & $1992,1998,2006$ & Nigeria (NGA) & 1999,2003 \\
\hline Peru (PER) & $1992,1996,2000$ & Senegal (SEN) & 1992,2005 \\
\hline Philippines (PHL) & $1993,1998,2003$ & Vietnam (VNM) & 1997,2002 \\
\hline \hline
\end{tabular}

Source: Illustration by the authors. 
Table A2 - Country Overview

\begin{tabular}{|c|c|c|c|c|}
\hline Country & $\begin{array}{l}\text { Per Capita } \\
\text { USD PPP }\end{array}$ & $\begin{array}{r}\text { Poverty Headcount } \\
(1 \$)\end{array}$ & HDI & HDI Rank \\
\hline Bangladesh (2004) & 1870 & 41.30 & 0.530 & 137 \\
\hline Benin (2006) & 1141 & 30.90 & 0.437 & 163 \\
\hline Bolivia (2006) & 2819 & 23.20 & 0.695 & 117 \\
\hline Brazil (1996) & 2038 & 56.12 & 0.513 & 151 \\
\hline Burkina Faso (2003) & 1174 & 27.19 & 0.317 & 175 \\
\hline Cambodia (2005) & 2727 & 34.08 & 0.598 & 131 \\
\hline Cameroon (2004) & 2174 & 17.10 & 0.506 & 144 \\
\hline Chad (2004) & 2090 & n.a. & 0.368 & 171 \\
\hline Colombia (2005) & 7304 & 7.03 & 0.791 & 75 \\
\hline Cote d'Ivoire (2006) & 1551 & 14.78 & 0.421 & 164 \\
\hline D. Republic (2002) & 6640 & 2.78 & 0.738 & 98 \\
\hline Ethiopia (2005) & 1055 & 22.98 & 0.406 & 169 \\
\hline Ghana (2003) & 2238 & 44.8 & 0.520 & 138 \\
\hline Guatemala (1999) & 3674 & 13.46 & 0.626 & 108 \\
\hline Guinea (2005) & 2316 & n.a. & 0.456 & 160 \\
\hline Haiti (2005) & 1663 & 53.89 & 0.529 & 146 \\
\hline India (2005) & 3452 & 34.33 & 0.619 & 128 \\
\hline Indonesia (2003) & 3361 & 7.51 & 0.697 & 110 \\
\hline Kenya (2003) & 1037 & 22.81 & 0.474 & 154 \\
\hline Madagascar (2004) & 857 & 61.03 & 0.509 & 143 \\
\hline Malawi (2004) & 646 & 20.76 & 0.400 & 166 \\
\hline Mali (2001) & 810 & 36.14 & 0.337 & 172 \\
\hline Mozambique (2003) & 1117 & 36.18 & 0.379 & 168 \\
\hline Namibia (2000) & 6431 & n.a. & 0.610 & 122 \\
\hline Nicaragua (2001) & 2450 & 45.12 & 0.643 & 121 \\
\hline Nigeria (2003) & 1050 & 70.82 & 0.453 & 158 \\
\hline Nepal (2006) & 1550 & 24.10 & 0.534 & 142 \\
\hline Niger (2006) & 781 & 60.60 & 0.374 & 174 \\
\hline Peru (2000) & 4799 & 10.53 & 0.747 & 82 \\
\hline Philippines (2003) & 4321 & 14.78 & 0.758 & 84 \\
\hline Tanzania (2004) & 674 & 57.82 & 0.430 & 162 \\
\hline Rwanda (2005) & 1206 & 60.29 & 0.452 & 161 \\
\hline Senegal (2005) & 1792 & 17.01 & 0.499 & 156 \\
\hline Uganda (2006) & 1454 & n.a. & 0.505 & 154 \\
\hline Vietnam (2002) & 2300 & n.a. & 0.691 & 112 \\
\hline Zambia (2001) & 780 & 63.80 & 0.386 & 163 \\
\hline Zimbabwe (2006) & 2038 & 56.12 & 0.513 & 151 \\
\hline
\end{tabular}

Source: World Development Indicators (2007), Human Development Reports.

Note: For some countries, the information in the poverty headcount were not available for the respective year. In this case, the values of the years nearest to the actual year was used. 
Table A3 - Net Attendance Rates by Asset Index Quintiles (Secondary Education)

\begin{tabular}{|c|c|c|c|c|c|c|c|c|}
\hline \multirow{2}{*}{ Country } & \multirow{2}{*}{ Year } & \multicolumn{5}{|c|}{ Quintiles } & \multirow{2}{*}{ Mean } & \multirow{2}{*}{ Ratio 5:1 } \\
\hline & & 1 & 2 & 3 & 4 & 5 & & \\
\hline \multirow{3}{*}{ Bangladesh } & 1993 & 36.6 & 48.4 & 50.0 & 62.2 & 71.1 & 53.6 & 1.94 \\
\hline & 1999 & 49.2 & 50.4 & 60.6 & 65.1 & 71.6 & 59.4 & 1.46 \\
\hline & 2004 & 47.7 & 52.8 & 55.4 & 63.5 & 68.9 & 57.7 & 1.45 \\
\hline \multirow{3}{*}{ Benin } & 1996 & 14.2 & 22.2 & 32.5 & 43.3 & 53.3 & 33.1 & 3.74 \\
\hline & 2001 & 28.6 & 35.7 & 46.0 & 55.2 & 64.6 & 46.0 & 2.26 \\
\hline & 2006 & 43.0 & 47.2 & 60.1 & 66.0 & 76.2 & 58.5 & 1.77 \\
\hline \multirow{2}{*}{ Bolivia } & 1994 & 49.6 & 60.5 & 78.6 & 86.9 & 89.4 & 73.0 & 1.80 \\
\hline & 1998 & 55.4 & 71.3 & 87.7 & 91.7 & 92.5 & 79.7 & 1.67 \\
\hline \multirow{2}{*}{ Brazil } & 1991 & 41.2 & 53 & 71.7 & 79.7 & 83.9 & 65.9 & 2.04 \\
\hline & 1996 & 73.5 & 82.2 & 88.1 & 90.6 & 91.7 & 85.2 & 1.25 \\
\hline \multirow{3}{*}{ Burkina Faso } & 1992 & 6.2 & 8.7 & 14.9 & 36.4 & 52.3 & 23.7 & 8.45 \\
\hline & 1998 & 5.6 & 6.7 & 7.7 & 17.7 & 46.9 & 16.9 & 8.42 \\
\hline & 2003 & 9.5 & 11.2 & 14.9 & 21.4 & 46.5 & 20.7 & 4.88 \\
\hline \multirow{2}{*}{ Cambodia } & 2000 & 45.4 & 52.1 & 55.0 & 64.0 & 76.0 & 58.5 & 1.68 \\
\hline & 2005 & 58.3 & 70.4 & 74.5 & 81.3 & 84.3 & 74.6 & 1.34 \\
\hline \multirow{3}{*}{ Cameroon } & 1991 & 43.0 & 56.9 & 64.7 & 77.8 & 86.4 & 65.8 & 2.01 \\
\hline & 1998 & 42.7 & 55.3 & 66.1 & 69.0 & 81.8 & 63.0 & 1.92 \\
\hline & 2004 & 60.7 & 68.4 & 72.4 & 77.6 & 87.6 & 73.3 & 1.44 \\
\hline \multirow{2}{*}{ Chad } & 1996 & 21.5 & 24.5 & 34.7 & 47.1 & 60.9 & 37.7 & 2.83 \\
\hline & 2004 & 19.9 & 27.3 & 43.2 & 56.3 & 73.8 & 44.1 & 3.72 \\
\hline \multirow{3}{*}{ Colombia } & 1995 & 63.3 & 71.8 & 82.8 & 89.9 & 92.5 & 80.1 & 1.46 \\
\hline & 2000 & 66.1 & 76.1 & 85.2 & 90.2 & 88.6 & 81.2 & 1.34 \\
\hline & 2005 & 75.7 & 82.8 & 87.9 & 91.2 & 92.5 & 86.0 & 1.22 \\
\hline \multirow{3}{*}{ Cote d'Ivoire } & 1994 & 21.2 & 33.0 & 35.0 & 45.8 & 57.3 & 38.4 & 2.71 \\
\hline & 1999 & 26.5 & 30.8 & 36.2 & 53.0 & 59.1 & 41.1 & 2.23 \\
\hline & 2004 & 30.6 & 35.7 & 41.4 & 49.2 & 63.0 & 44.0 & 2.06 \\
\hline \multirow{3}{*}{$\begin{array}{l}\text { Dominican } \\
\text { Republic }\end{array}$} & 1991 & 57.5 & 65.5 & 77.8 & 83.9 & 87.8 & 74.5 & 1.53 \\
\hline & 1996 & 68.7 & 79.7 & 87.2 & 90.4 & 90.8 & 83.3 & 1.32 \\
\hline & 2002 & 79.2 & 87.7 & 91.4 & 93.8 & 95.4 & 89.5 & 1.21 \\
\hline \multirow{2}{*}{ Ethiopia } & 1998 & 28.2 & 29.0 & 28.9 & 46.5 & 74.6 & 41.4 & 2.64 \\
\hline & 2005 & 39.0 & 42.6 & 49.7 & 64.2 & 80.6 & 55.2 & 2.07 \\
\hline \multirow{3}{*}{ Ghana } & 1993 & 46.5 & 66.0 & 71.0 & 70.4 & 72.1 & 65.2 & 1.55 \\
\hline & 1998 & 40.8 & 59.4 & 72.6 & 75.6 & 80.4 & 65.8 & 1.97 \\
\hline & 2003 & 43.2 & 68.3 & 75.8 & 79.8 & 79.4 & 69.3 & 1.84 \\
\hline \multirow{2}{*}{ Guatemala } & 1995 & 22.5 & 24.6 & 34.0 & 51.2 & 69.7 & 40.4 & 3.09 \\
\hline & 1999 & 31.3 & 34.3 & 41.1 & 56.5 & 75.8 & 47.8 & 2.42 \\
\hline \multirow{2}{*}{ Guinea } & 1999 & 11.2 & 11.9 & 21.1 & 34.3 & 46.7 & 25.0 & 4.18 \\
\hline & 2005 & 25.1 & 33.7 & 42.2 & 59.1 & 74.8 & 47.0 & 2.98 \\
\hline & 1994 & 52.1 & 70.8 & 82.0 & 82.6 & 90.6 & 75.6 & 1.74 \\
\hline Haiti & 2000 & 67.2 & 78.7 & 80.0 & 79.5 & 90.5 & 70.2 & 0.68 \\
\hline & 2005 & 69.3 & 80.0 & 86.2 & 88.6 & 91.8 & 83.2 & 1.35 \\
\hline & 1992 & 28.0 & 37.0 & 44.4 & 49.1 & 54.1 & 42.5 & 1.93 \\
\hline India & 1999 & 47.8 & 58.1 & 68.3 & 77.9 & 88.9 & 68.2 & 1.86 \\
\hline & 2005 & 58.4 & 69.8 & 75.7 & 82.6 & 90.8 & 75.5 & 1.56 \\
\hline & 1991 & 33.8 & 38.3 & 49.5 & 67.0 & 77.1 & 53.1 & 2.28 \\
\hline Indonesia & 1997 & 41.3 & 51.3 & 60.1 & 71.7 & 81.0 & 61.1 & 1.96 \\
\hline & 2003 & 40.1 & 52.9 & 64.7 & 75.0 & 81.3 & 62.8 & 2.03 \\
\hline
\end{tabular}

Table continues on next page. 
Table A3 - continued

\begin{tabular}{|c|c|c|c|c|c|c|c|c|}
\hline \multirow{2}{*}{ Country } & \multirow{2}{*}{ Year } & \multicolumn{5}{|c|}{ Quintiles } & \multirow[t]{2}{*}{ Mean } & \multirow{2}{*}{$\begin{array}{r}\text { Ratio } \\
5: 1\end{array}$} \\
\hline & & 1 & 2 & 3 & 4 & 5 & & \\
\hline \multirow{3}{*}{ Kenya } & 1993 & 78.0 & 84.1 & 83.9 & 84.5 & 75.8 & 81.3 & 0.97 \\
\hline & 1998 & 77.7 & 84.1 & 82.4 & 81.3 & 72.6 & 79.6 & 0.93 \\
\hline & 2003 & 66.3 & 79.2 & 82.6 & 83.6 & 71.6 & 76.7 & 1.08 \\
\hline \multirow{3}{*}{ Madagascar } & 1992 & 28.8 & 36.8 & 41.9 & 59.7 & 81.8 & 49.8 & 2.84 \\
\hline & 1997 & 29.1 & 31.6 & 34.5 & 52.7 & 77.2 & 45.0 & 2.65 \\
\hline & 2004 & 44.8 & 56.5 & 67.1 & 81.1 & 84.8 & 66.9 & 1.89 \\
\hline \multirow{3}{*}{ Malawi } & 1992 & 54.5 & 59.7 & 68.3 & 73.4 & 80.1 & 67.2 & 1.47 \\
\hline & 2000 & 70.6 & 72.9 & 76.5 & 77.9 & 83.9 & 76.4 & 1.19 \\
\hline & 2004 & 73.4 & 75.8 & 78.5 & 78.5 & 84.4 & 78.1 & 1.15 \\
\hline \multirow{2}{*}{ Mali } & 1996 & 5.4 & 7.9 & 15.8 & 23.3 & 48.8 & 20.2 & 9.04 \\
\hline & 2001 & 11.3 & 15.9 & 20.8 & 28.7 & 52.7 & 25.9 & 4.67 \\
\hline \multirow{2}{*}{ Mozambique } & 1997 & 43.8 & 47.1 & 53.6 & 64.7 & 76.7 & 57.2 & 1.75 \\
\hline & 2003 & 64.3 & 63.5 & 67.8 & 80.0 & 87.6 & 72.7 & 1.36 \\
\hline \multirow{2}{*}{ Namibia } & 1992 & 84 & 90.1 & 84.8 & 82.1 & 89.0 & 86.0 & 1.06 \\
\hline & 2000 & 72.8 & 81.5 & 75.0 & 85.4 & 92.1 & 81.3 & 1.26 \\
\hline \multirow{3}{*}{ Nepal } & 1996 & 49.7 & 49.2 & 54.5 & 70.6 & 84.3 & 61.7 & 1.70 \\
\hline & 2001 & 53.5 & 64.2 & 68.9 & 76.9 & 86.9 & 70.1 & 1.62 \\
\hline & 2006 & 74.7 & 77.3 & 82.3 & 88.4 & 92.1 & 83.0 & 1.23 \\
\hline \multirow{2}{*}{ Nicaragua } & 1997 & 30.0 & 41.3 & 61.3 & 71.0 & 83.7 & 57.5 & 2.79 \\
\hline & 2001 & 33.9 & 43.9 & 59.9 & 71.5 & 83.1 & 58.5 & 2.45 \\
\hline \multirow{3}{*}{ Niger } & 1992 & 6.5 & 6.0 & 10.0 & 26.5 & 48.7 & 19.5 & 7.52 \\
\hline & 1998 & 5.3 & 5.9 & 5.6 & 16.9 & 44.8 & 15.7 & 8.42 \\
\hline & 2006 & 12.4 & 13.4 & 16.5 & 25.5 & 57.1 & 25.0 & 4.62 \\
\hline \multirow{2}{*}{ Nigeria } & 1999 & 46.9 & 51.7 & 68.9 & 79.1 & 85.8 & 66.5 & 1.83 \\
\hline & 2003 & 48.2 & 64.0 & 70.5 & 81.6 & 86.2 & 70.1 & 1.79 \\
\hline \multirow{3}{*}{ Peru } & 1992 & 66.7 & 82.9 & 89.1 & 90.8 & 88.3 & 83.6 & 1.32 \\
\hline & 1996 & 71.5 & 82.5 & 90.0 & 93.6 & 94.5 & 86.4 & 1.32 \\
\hline & 2000 & 76.2 & 82.2 & 90.8 & 94.5 & 94.4 & 87.6 & 1.24 \\
\hline \multirow{3}{*}{ Philippines } & 1993 & 74.0 & 83.8 & 90.1 & 94.0 & 94.6 & 87.3 & 1.28 \\
\hline & 1998 & 71.9 & 80.8 & 85.2 & 92.3 & 91.0 & 84.3 & 1.27 \\
\hline & 2003 & 73.1 & 84.1 & 88.4 & 92.9 & 93.6 & 86.4 & 1.28 \\
\hline \multirow{3}{*}{ Rwanda } & 1992 & 21.8 & 23.6 & 27.4 & 30.9 & 48.4 & 30.4 & 2.22 \\
\hline & 2000 & 18.6 & 20.3 & 18.1 & 20.4 & 20.0 & 19.5 & 1.07 \\
\hline & 2005 & 51.7 & 54.9 & 58.0 & 59.5 & 58.3 & 56.5 & 1.13 \\
\hline \multirow{2}{*}{ Senegal } & 1992 & 7.2 & 9.7 & 19.2 & 23.1 & 47.4 & 21.3 & 6.55 \\
\hline & 2005 & 29.5 & 34.4 & 36.5 & 44.4 & 55.8 & 40.1 & 1.90 \\
\hline & 1992 & 34.8 & 33.4 & 35.4 & 37.8 & 42.6 & 36.8 & 1.22 \\
\hline Tanzania & 1996 & 43.6 & 47.7 & 48.5 & 48.2 & 46.9 & 47.0 & 1.08 \\
\hline & 2004 & 42.5 & 44.4 & 48.0 & 50.6 & 57.7 & 48.6 & 1.36 \\
\hline & 1995 & 42.0 & 44.2 & 55.9 & 60.0 & 62.6 & 53.0 & 1.50 \\
\hline Uganda & 2000 & 66.5 & 67.8 & 76.7 & 70.1 & 75.2 & 71.4 & 1.13 \\
\hline & 2006 & 53.7 & 73.6 & 78.1 & 78.7 & 79.9 & 72.8 & 1.50 \\
\hline Vietnam & 1997 & 56.5 & 64.4 & 70.9 & 80.2 & 90.0 & 72.4 & 1.59 \\
\hline vietnam & 2002 & 63.3 & 77.9 & 80.9 & 84.8 & 90.7 & 79.5 & 1.43 \\
\hline & 1992 & 41.9 & 43.7 & 51.9 & 56.8 & 72.5 & 53.4 & 1.73 \\
\hline Zambia & 1996 & 36.6 & 43.2 & 48.8 & 53.4 & 73.1 & 51.0 & 2.00 \\
\hline & 2001 & 43.5 & 51.7 & 56.9 & 60.2 & 75.2 & 57.5 & 1.73 \\
\hline & 1994 & 57.7 & 66.3 & 66.2 & 66.3 & 68.5 & 65.0 & 1.19 \\
\hline Zimbabwe & 1999 & 61.2 & 66.0 & 71.9 & 63.6 & 74.7 & 67.5 & 1.22 \\
\hline & 2006 & 55.4 & 66.7 & 69.8 & 67.2 & 74.6 & 66.8 & 1.34 \\
\hline
\end{tabular}

Source: Demographic and Health Surveys; own calculations. 
Table A4 - Average Years of Education by Asset Index Quintiles (Age group 17-22)

\begin{tabular}{|c|c|c|c|c|c|c|c|c|}
\hline \multirow{2}{*}{ Country } & \multirow{2}{*}{ Year } & \multicolumn{5}{|c|}{ Quintiles } & \multirow{2}{*}{ Mean } & \multirow{2}{*}{ Ratio 5:1 } \\
\hline & & 1 & 2 & 3 & 4 & 5 & & \\
\hline \multirow{3}{*}{ Bangladesh } & 1993 & 1.5 & 2.9 & 3.3 & 5.1 & 7.5 & 4.1 & 4.88 \\
\hline & 1999 & 3.0 & 3.7 & 5.4 & 6.6 & 8.6 & 5.4 & 2.90 \\
\hline & 2004 & 3.7 & 4.5 & 5.5 & 6.7 & 8.1 & 5.7 & 2.21 \\
\hline \multirow{3}{*}{ Benin } & 1996 & 0.6 & 1.1 & 1.6 & 2.8 & 5.1 & 2.2 & 8.05 \\
\hline & 2001 & 1.1 & 1.7 & 2.3 & 3.7 & 6.5 & 3.0 & 5.97 \\
\hline & 2006 & 2.2 & 2.5 & 3.5 & 4.7 & 7.7 & 4.1 & 3.47 \\
\hline \multirow{3}{*}{ Bolivia } & 1994 & 4.8 & 6.3 & 8.4 & 9.8 & 10.6 & 8.0 & 2.23 \\
\hline & 1998 & 4.9 & 6.7 & 8.8 & 9.9 & 10.2 & 8.1 & 2.07 \\
\hline & 2003 & 6.4 & 8.3 & 9.8 & 10.5 & 11.3 & 9.2 & 1.76 \\
\hline \multirow{2}{*}{ Brazil } & 1991 & 1.9 & 3.1 & 5.1 & 6.4 & 7.5 & 4.8 & 3.89 \\
\hline & 1996 & 3.6 & 5.4 & 7.2 & 7.3 & 8.8 & 6.5 & 2.43 \\
\hline \multirow{3}{*}{ Burkina Faso } & 1992 & 0.4 & 0.7 & 1.9 & 3.7 & 6.0 & 2.5 & 15.33 \\
\hline & 1998 & 0.6 & 0.5 & 0.9 & 1.8 & 5.5 & 1.8 & 9.16 \\
\hline & 2003 & 0.8 & 0.8 & 1.4 & 2.4 & 5.6 & 2.2 & 6.71 \\
\hline \multirow{2}{*}{ Cambodia } & 2000 & 2.4 & 3.2 & 3.5 & 4.9 & 7.2 & 4.3 & 2.96 \\
\hline & 2005 & 3.2 & 3.9 & 4.9 & 6.2 & 8.3 & 5.3 & 2.62 \\
\hline \multirow{3}{*}{ Cameroon } & 1991 & 3.6 & 4.2 & 6.0 & 7.3 & 8.6 & 5.9 & 2.38 \\
\hline & 1998 & 3.4 & 5.1 & 7.1 & 8.2 & 9.3 & 6.6 & 2.76 \\
\hline & 2004 & 3.8 & 4.9 & 5.8 & 7.5 & 8.8 & 6.1 & 2.34 \\
\hline \multirow{2}{*}{ Chad } & 1996 & 1.0 & 1.2 & 1.9 & 3.4 & 0.9 & 2.5 & 4.67 \\
\hline & 2004 & 1.0 & 1.4 & 3.1 & 4.2 & 6.8 & 3.3 & 6.94 \\
\hline \multirow{3}{*}{ Colombia } & 1995 & 4.3 & 6.5 & 8.0 & 9.1 & 9.5 & 7.5 & 2.23 \\
\hline & 2000 & 5.5 & 7.6 & 9.3 & 9.7 & 9.9 & 8.4 & 1.79 \\
\hline & 2005 & 6.6 & 8.1 & 9.3 & 9.9 & 10.7 & 8.9 & 1.62 \\
\hline \multirow{3}{*}{ Cote d'Ivoire } & 1994 & 2.1 & 2.9 & 3.8 & 4.6 & 6.2 & 3.9 & 2.96 \\
\hline & 1999 & 2.2 & 3.1 & 4.5 & 5.9 & 7.2 & 4.6 & 3.24 \\
\hline & 2004 & 2.0 & 2.6 & 3.5 & 4.3 & 6.3 & 3.7 & 3.15 \\
\hline \multirow{3}{*}{$\begin{array}{l}\text { Dominican } \\
\text { Republic }\end{array}$} & 1991 & 4.4 & 6.1 & 7.7 & 8.4 & 9.3 & 7.2 & 2.13 \\
\hline & 1996 & 3.8 & 6.3 & 7.4 & 8.9 & 9.5 & 7.2 & 2.50 \\
\hline & 2002 & 5.3 & 7.5 & 8.8 & 9.6 & 10.2 & 8.3 & 1.91 \\
\hline \multirow{2}{*}{ Ethiopia } & 1998 & 1.2 & 1.0 & 1.1 & 2.2 & 7.1 & 2.5 & 6.06 \\
\hline & 2005 & 1.6 & 1.8 & 2.3 & 3.7 & 7.4 & 3.3 & 4.54 \\
\hline \multirow{3}{*}{ Ghana } & 1993 & 3.5 & 5.6 & 6.2 & 7.4 & 9.0 & 6.4 & 2.60 \\
\hline & 1998 & 3.1 & 5.2 & 7.1 & 7.8 & 9.8 & 6.6 & 3.14 \\
\hline & 2003 & 3.2 & 5.2 & 6.3 & 7.7 & 9.2 & 6.3 & 2.85 \\
\hline \multirow{2}{*}{ Guatemala } & 1995 & 1.8 & 2.4 & 3.6 & 5.5 & 8.1 & 4.3 & 4.42 \\
\hline & 1999 & 1.9 & 2.9 & 4.1 & 6.1 & 8.3 & 4.7 & 4.37 \\
\hline \multirow{2}{*}{ Guinea } & 1999 & 0.7 & 0.8 & 1.5 & 3.1 & 5.7 & 2.3 & 8.07 \\
\hline & 2005 & 1.1 & 1.8 & 2.3 & 4.0 & 6.0 & 3.0 & 5.67 \\
\hline & 1994 & 1.7 & 3.2 & 4.9 & 6.0 & 7.8 & 4.7 & 4.50 \\
\hline Haiti & 2000 & 2.8 & 3.8 & 4.2 & 6.0 & 7.6 & 4.9 & 2.71 \\
\hline & 2005 & 3.3 & 4.4 & 5.6 & 6.9 & 8.3 & 5.7 & 2.53 \\
\hline & 1992 & 2.8 & 4.2 & 5.7 & 7.4 & 10.0 & 6.0 & 3.59 \\
\hline India & 1999 & 3.5 & 4.9 & 6.4 & 8.1 & 10.4 & 6.6 & 2.98 \\
\hline & 2005 & 4.4 & 6.2 & 7.8 & 9.2 & 11.1 & 7.7 & 2.52 \\
\hline & 1991 & 5.5 & 6.5 & 7.7 & 9.2 & 10.3 & 7.9 & 1.87 \\
\hline Indonesia & 1997 & 5.7 & 7.1 & 8.1 & 9.3 & 10.6 & 8.2 & 1.85 \\
\hline & 2003 & 6.5 & 7.9 & 9.1 & 10.1 & 11.2 & 8.9 & 1.72 \\
\hline
\end{tabular}

Table continues on next page. 
Table A4 - continued

\begin{tabular}{|c|c|c|c|c|c|c|c|c|}
\hline \multirow{2}{*}{ Country } & \multirow{2}{*}{ Year } & \multicolumn{5}{|c|}{ Quintiles } & \multirow{2}{*}{ Mean } & \multirow{2}{*}{ Ratio 5:1 } \\
\hline & & 1 & 2 & 3 & 4 & 5 & & \\
\hline \multirow{3}{*}{ Kenya } & 1993 & 6.2 & 7.1 & 7.3 & 7.4 & 8.6 & 7.3 & 1.39 \\
\hline & 1998 & 6.3 & 7.2 & 7.6 & 7.8 & 8.9 & 7.6 & 1.43 \\
\hline & 2003 & 4.9 & 6.4 & 7.1 & 8.2 & 9.5 & 7.2 & 1.92 \\
\hline \multirow{3}{*}{ Madagascar } & 1992 & 0.1 & 0.2 & 0.2 & 0.4 & 1.0 & 0.4 & 9.73 \\
\hline & 1997 & 1.9 & 2.3 & 2.3 & 4.1 & 7.6 & 3.6 & 4.07 \\
\hline & 2004 & 1.6 & 2.9 & 4.8 & 8.5 & 10.1 & 5.6 & 6.31 \\
\hline \multirow{3}{*}{ Malawi } & 1992 & 3.2 & 3.6 & 4.3 & 5.3 & 7.0 & 4.7 & 2.21 \\
\hline & 2000 & 4.4 & 4.6 & 5.3 & 5.8 & 8.0 & 5.6 & 1.83 \\
\hline & 2004 & 4.9 & 5.3 & 5.4 & 5.7 & 8.5 & 6.0 & 1.75 \\
\hline \multirow{2}{*}{ Mali } & 1996 & 0.3 & 0.6 & 0.9 & 1.6 & 3.7 & 1.4 & 12.36 \\
\hline & 2001 & 0.4 & 0.7 & 0.9 & 1.4 & 4.8 & 1.6 & 13.07 \\
\hline \multirow{2}{*}{ Mozambique } & 1997 & 1.8 & 2.1 & 2.7 & 4.1 & 5.7 & 3.3 & 3.16 \\
\hline & 2003 & 1.9 & 2.2 & 2.9 & 3.9 & 5.0 & 3.2 & 2.64 \\
\hline \multirow{2}{*}{ Namibia } & 1992 & 5.3 & 5.3 & 5.6 & 6.3 & 8.3 & 6.2 & 1.57 \\
\hline & 2000 & 5.9 & 6.7 & 6.9 & 8.6 & 9.7 & 7.6 & 1.64 \\
\hline \multirow{3}{*}{ Nepal } & 1996 & 2.7 & 2.6 & 3.1 & 4.5 & 7.0 & 4.0 & 2.57 \\
\hline & 2001 & 2.3 & 3.3 & 4.1 & 5.0 & 7.7 & 4.5 & 3.31 \\
\hline & 2006 & 3.3 & 4.1 & 5.2 & 6.6 & 8.9 & 5.6 & 2.67 \\
\hline \multirow{2}{*}{ Nicaragua } & 1997 & 2.7 & 3.9 & 6.1 & 7.6 & 9.1 & 5.9 & 3.33 \\
\hline & 2001 & 2.5 & 4.1 & 6.2 & 7.6 & 9.2 & 5.9 & 3.76 \\
\hline \multirow{3}{*}{ Niger } & 1992 & 0.7 & 0.6 & 1.0 & 2.7 & 4.9 & 2.0 & 7.17 \\
\hline & 1998 & 0.8 & 0.7 & 1.0 & 2.3 & 4.8 & 1.9 & 5.90 \\
\hline & 2006 & 0.5 & 0.6 & 1.0 & 2.3 & 5.8 & 2.0 & 11.14 \\
\hline \multirow{2}{*}{ Nigeria } & 1999 & 4.1 & 4.9 & 7.1 & 8.1 & 9.9 & 6.8 & 2.41 \\
\hline & 2003 & 3.9 & 5.4 & 6.3 & 8.2 & 9.9 & 6.7 & 2.52 \\
\hline \multirow{3}{*}{ Peru } & 1992 & 5.6 & 7.3 & 8.8 & 9.8 & 9.9 & 8.3 & 1.79 \\
\hline & 1996 & 5.0 & 6.5 & 8.4 & 9.4 & 9.8 & 7.8 & 1.95 \\
\hline & 2000 & 6.5 & 7.6 & 9.4 & 10.5 & 11.1 & 9.0 & 1.71 \\
\hline \multirow{3}{*}{ Philippines } & 1993 & 6.2 & 7.8 & 9.0 & 9.9 & 10.7 & 8.7 & 1.72 \\
\hline & 1998 & 6.0 & 7.6 & 9.1 & 10.0 & 10.5 & 8.7 & 1.75 \\
\hline & 2003 & 6.3 & 8.2 & 9.5 & 10.4 & 11.0 & 9.1 & 1.74 \\
\hline \multirow{3}{*}{ Rwanda } & 1992 & 3.8 & 4.1 & 5.2 & 5.2 & 6.8 & 5.0 & 1.78 \\
\hline & 2000 & 3.4 & 3.4 & 3.7 & 4.5 & 6.2 & 4.2 & 1.81 \\
\hline & 2005 & 2.9 & 3.4 & 3.4 & 3.8 & 5.5 & 3.8 & 1.89 \\
\hline \multirow{2}{*}{ Senegal } & 1992 & 0.6 & 1.2 & 1.9 & 3.4 & 6.0 & 2.6 & 10.21 \\
\hline & 2005 & 1.4 & 1.8 & 2.3 & 3.9 & 5.1 & 2.9 & 3.72 \\
\hline & 1992 & 5.0 & 5.1 & 5.5 & 6.0 & 7.2 & 5.8 & 1.44 \\
\hline Tanzania & 1996 & 4.8 & 5.2 & 5.3 & 5.6 & 7.1 & 5.6 & 1.50 \\
\hline & 2004 & 3.9 & 4.8 & 5.0 & 6.2 & 8.1 & 5.6 & 2.06 \\
\hline & 1995 & 3.6 & 4.2 & 4.8 & 5.9 & 7.8 & 5.3 & 2.16 \\
\hline Uganda & 2000 & 3.9 & 4.8 & 6.1 & 6.7 & 8.9 & 6.1 & 2.31 \\
\hline & 2006 & 3.8 & 5.7 & 6.0 & 6.7 & 8.7 & 6.2 & 2.29 \\
\hline Vietnam & 1997 & 4.1 & 6.7 & 7.6 & 8.7 & 9.9 & 7.4 & 2.42 \\
\hline viectramin & 2002 & 5.2 & 7.8 & 8.7 & 9.4 & 10.4 & 8.3 & 1.99 \\
\hline & 1992 & 4.4 & 4.5 & 5.7 & 6.8 & 7.9 & 5.9 & 1.81 \\
\hline Zambia & 1996 & 4.3 & 4.9 & 5.3 & 6.7 & 8.5 & 5.9 & 1.99 \\
\hline & 2001 & 4.0 & 4.7 & 5.5 & 6.7 & 9.0 & 6.0 & 2.23 \\
\hline & 1994 & 7.0 & 7.8 & 8.0 & 8.4 & 9.7 & 8.2 & 1.40 \\
\hline Zimbabwe & 1999 & 7.4 & 7.9 & 8.3 & 9.0 & 10.4 & 8.6 & 1.40 \\
\hline & 2006 & 7.0 & 7.9 & 8.3 & 8.9 & 10.0 & 8.4 & 1.43 \\
\hline
\end{tabular}

Source: Demographic and Health Surveys; own calculations. 
Table A5 - Educational Attainment by Asset Index Quintiles (Secondary Education Completion - Age group 17-22)

\begin{tabular}{|c|c|c|c|c|c|c|c|c|}
\hline \multirow{2}{*}{ Country } & \multirow{2}{*}{ Year } & \multicolumn{5}{|c|}{ Quintiles } & \multirow{2}{*}{ Mean } & \multirow{2}{*}{ Ratio 5:1 } \\
\hline & & 1 & 2 & 3 & 4 & 5 & & \\
\hline \multirow{3}{*}{ Bangladesh } & 1993 & 1.2 & 5.3 & 7.1 & 14.3 & 36.5 & 12.9 & 30.83 \\
\hline & 1999 & 3.8 & 5.5 & 13.3 & 23.7 & 50.3 & 19.3 & 13.32 \\
\hline & 2004 & 3.6 & 7.8 & 11.6 & 17.9 & 39.0 & 16.0 & 10.73 \\
\hline \multirow{3}{*}{ Benin } & 1996 & 1.1 & 0.4 & 0.8 & 0.5 & 2.6 & 1.1 & 2.45 \\
\hline & 2001 & 0.2 & 0.4 & 0.2 & 2.0 & 5.6 & 1.7 & 29.12 \\
\hline & 2006 & 1.1 & 1.4 & 1.4 & 2.9 & 11.9 & 3.7 & 10.59 \\
\hline \multirow{3}{*}{ Bolivia } & 1994 & 4.4 & 6.3 & 24 & 39.8 & 52.9 & 25.5 & 11.97 \\
\hline & 1998 & 6.1 & 10.6 & 34.7 & 51 & 55.9 & 31.7 & 9.17 \\
\hline & 2003 & 8.2 & 18.4 & 34.9 & 44.6 & 56.7 & 32.6 & 6.93 \\
\hline \multirow{2}{*}{ Brazil } & 1991 & 0.7 & 0.6 & 2.0 & 2.3 & 6.5 & 2.4 & 9.32 \\
\hline & 1996 & 2.4 & 8.5 & 19.6 & 21.2 & 34.6 & 17.3 & 14.30 \\
\hline \multirow{3}{*}{ Burkina Faso } & 1992 & 0.3 & 0.6 & 0.7 & 1.9 & 6.1 & 1.9 & 17.32 \\
\hline & 1998 & 0.4 & 0.5 & 0.3 & 1.9 & 3.0 & 1.2 & 8.35 \\
\hline & 2003 & 0.1 & 0.0 & 0.3 & 1.0 & 4.5 & 1.2 & 52.14 \\
\hline \multirow{2}{*}{ Cambodia } & 2000 & 0.4 & 0.3 & 0.4 & 1.3 & 11.6 & 2.8 & 32.91 \\
\hline & 2005 & 0.7 & 0.6 & 1.3 & 3.7 & 16.2 & 4.5 & 22.02 \\
\hline \multirow{3}{*}{ Cameroon } & 1991 & 0.5 & 1.0 & 1.2 & 2.5 & 7.5 & 2.5 & 14.78 \\
\hline & 1998 & 1.4 & 0.6 & 1.1 & 4.8 & 6.1 & 2.8 & 4.36 \\
\hline & 2004 & 0.3 & 0.4 & 0.5 & 3.6 & 5.6 & 2.1 & 18.30 \\
\hline \multirow{2}{*}{ Chad } & 1996 & 0.7 & 0.1 & 0.6 & 0.4 & 1.4 & 0.6 & 2.01 \\
\hline & 2004 & 0.0 & 0.0 & 1.4 & 1.8 & 10.4 & 2.7 & n.d. \\
\hline \multirow{3}{*}{ Colombia } & 1995 & 4.4 & 16.0 & 29.0 & 40.3 & 47.6 & 27.5 & 10.70 \\
\hline & 2000 & 12.2 & 28.3 & 50.3 & 57.2 & 58.9 & 41.4 & 4.85 \\
\hline & 2005 & 19 & 34 & 49.4 & 59.1 & 71.9 & 46.7 & 3.79 \\
\hline \multirow{3}{*}{ Cote d'Ivoire } & 1994 & 0.6 & 0.8 & 1.9 & 1.8 & 4.1 & 1.8 & 7.17 \\
\hline & 1999 & 2.2 & 1.3 & 3.7 & 8.8 & 14.7 & 6.1 & 6.74 \\
\hline & 2004 & 1.0 & 0.8 & 1.0 & 2.1 & 5.4 & 2.1 & 5.39 \\
\hline \multirow{3}{*}{$\begin{array}{l}\text { Dominican } \\
\text { Republic }\end{array}$} & 1991 & 3.8 & 8.5 & 20.9 & 25.6 & 31.1 & 18.0 & 8.09 \\
\hline & 1996 & 4.1 & 9.7 & 16.0 & 28.7 & 35.0 & 18.7 & 8.46 \\
\hline & 2002 & 7.0 & 14.7 & 25.8 & 34.4 & 41.2 & 24.6 & 5.85 \\
\hline \multirow{2}{*}{ Ethiopia } & 1998 & 0.6 & 0.2 & 0.5 & 1.5 & 17.6 & 4.1 & 27.56 \\
\hline & 2005 & 0.4 & 0.6 & 0.6 & 2.1 & 15.8 & 3.9 & 41.88 \\
\hline \multirow{3}{*}{ Ghana } & 1993 & 0.6 & 0.5 & 1.5 & 2.9 & 15.6 & 4.2 & 25.06 \\
\hline & 1998 & 1.0 & 0.7 & 1.2 & 2.4 & 8.2 & 2.7 & 7.94 \\
\hline & 2003 & 3.3 & 1.6 & 3.1 & 10.8 & 29.4 & 9.7 & 8.81 \\
\hline \multirow{2}{*}{ Guatemala } & 1995 & 0.8 & 0.8 & 1.6 & 6.3 & 23.1 & 6.5 & 28.28 \\
\hline & 1999 & 1.0 & 0.9 & 2.8 & 8.1 & 23.4 & 7.2 & 23.86 \\
\hline \multirow{2}{*}{ Guinea } & 1999 & 1.8 & 1.3 & 1.2 & 1.8 & 4.4 & 2.1 & 2.44 \\
\hline & 2005 & 0.2 & 0.4 & 0.7 & 0.9 & 2.9 & 1.0 & 14.93 \\
\hline & 1994 & 4.2 & 1.9 & 2.7 & 4.3 & 9.0 & 4.4 & 2.16 \\
\hline Haiti & 2000 & 0.7 & 0.2 & 0.1 & 0.5 & 3.0 & 0.9 & 4.31 \\
\hline & 2005 & 0.3 & 0.2 & 0.5 & 2.4 & 7.9 & 2.3 & 30.67 \\
\hline & 1992 & 3.3 & 5.1 & 7.6 & 13.9 & 37.8 & 13.5 & 11.54 \\
\hline India & 1999 & 9.8 & 16.2 & 26.3 & 40.5 & 68.4 & 32.2 & 6.99 \\
\hline & 2005 & 3.8 & 8.4 & 16.5 & 27.9 & 50.7 & 21.4 & 13.47 \\
\hline & 1991 & 5.6 & 10.7 & 16.2 & 30.3 & 45.5 & 21.7 & 8.07 \\
\hline Indonesia & 1997 & 5.4 & 10.4 & 18.4 & 31.5 & 47.4 & 22.6 & 8.72 \\
\hline & 2003 & 7.6 & 17.2 & 30.2 & 43.0 & 58.4 & 31.3 & 7.71 \\
\hline
\end{tabular}

Table continues on next page. 
Table A5 - continued

\begin{tabular}{|c|c|c|c|c|c|c|c|c|}
\hline \multirow{2}{*}{ Country } & \multirow{2}{*}{ Year } & \multicolumn{5}{|c|}{ Quintiles } & \multirow{2}{*}{ Mean } & \multirow{2}{*}{ Ratio 5:1 } \\
\hline & & 1 & 2 & 3 & 4 & 5 & & \\
\hline \multirow{3}{*}{ Kenya } & 1993 & 0.4 & 1.0 & 0.4 & 1.3 & 2.4 & 1.1 & 5.46 \\
\hline & 1998 & 5.7 & 8.6 & 13.6 & 16.3 & 32.5 & 15.4 & 5.67 \\
\hline & 2003 & 3.7 & 7.0 & 9.7 & 18.9 & 42.2 & 16.3 & 11.31 \\
\hline \multirow{3}{*}{ Madagascar } & 1992 & 2.1 & 3.3 & 2.7 & 2.7 & 12.1 & 4.6 & 5.64 \\
\hline & 1997 & 0.1 & 0.8 & 0.8 & 1.8 & 11.3 & 3.0 & 92.46 \\
\hline & 2004 & 1.0 & 0.4 & 1.7 & 11.3 & 23.6 & 7.6 & 23.88 \\
\hline \multirow{3}{*}{ Malawi } & 1992 & 0.0 & 0.6 & 1.3 & 2.8 & 8.9 & 2.7 & n.d. \\
\hline & 2000 & 0.6 & 0.5 & 2.0 & 2.5 & 15.0 & 4.1 & 24.98 \\
\hline & 2004 & 1.1 & 3.1 & 2.7 & 3.3 & 23.3 & 6.7 & 20.34 \\
\hline \multirow{2}{*}{ Mali } & 1996 & 0.4 & 0.4 & 0.6 & 0.5 & 1.4 & 0.7 & 3.44 \\
\hline & 2001 & 0.5 & 1.1 & 0.8 & 1.0 & 3.7 & 1.4 & 7.32 \\
\hline \multirow{2}{*}{ Mozambique } & 1997 & 1.8 & 1.7 & 1.1 & 1.4 & 5.2 & 2.2 & 2.83 \\
\hline & 2003 & 0.2 & 0.3 & 0.2 & 0.2 & 3.0 & 0.8 & 15.51 \\
\hline \multirow{2}{*}{ Namibia } & 1992 & 1.1 & 0.5 & 1.1 & 1.6 & 12.3 & 3.3 & 11.62 \\
\hline & 2000 & 2.7 & 4.7 & 5.7 & 17.4 & 31.8 & 12.4 & 11.81 \\
\hline \multirow{3}{*}{ Nepal } & 1996 & 3.8 & 4.4 & 5.4 & 9.6 & 27.4 & 10.1 & 7.23 \\
\hline & 2001 & 2.7 & 5.6 & 7.4 & 12.5 & 39.5 & 13.5 & 14.86 \\
\hline & 2006 & 4.5 & 5.8 & 9.6 & 21.1 & 49.9 & 18.2 & 11.06 \\
\hline \multirow{2}{*}{ Nicaragua } & 1997 & 1.8 & 2.9 & 10.9 & 23.8 & 39.9 & 15.9 & 21.64 \\
\hline & 2001 & 1.3 & 3.1 & 11.1 & 20.5 & 42.0 & 15.6 & 31.33 \\
\hline \multirow{3}{*}{ Niger } & 1992 & 0.2 & 1.5 & 0.5 & 1.3 & 2.0 & 1.1 & 11.49 \\
\hline & 1998 & 1.1 & 0.6 & 0.7 & 1.0 & 0.6 & 0.8 & 0.55 \\
\hline & 2006 & 0.6 & 0.4 & 0.4 & 1.0 & 2.5 & 1.0 & 4.12 \\
\hline \multirow{2}{*}{ Nigeria } & 1999 & 14.1 & 13.6 & 20.4 & 26.7 & 40.9 & 23.1 & 2.91 \\
\hline & 2003 & 6.4 & 9.1 & 15 & 29.2 & 48.2 & 21.6 & 7.52 \\
\hline \multirow{3}{*}{ Peru } & 1992 & 11.7 & 27.9 & 52.1 & 70.6 & 73.9 & 47.2 & 6.32 \\
\hline & 1996 & 9.7 & 22.4 & 44.7 & 64.9 & 73.2 & 43.0 & 7.59 \\
\hline & 2000 & 13.1 & 23.1 & 47.3 & 66 & 77.9 & 45.4 & 5.95 \\
\hline \multirow{3}{*}{ Philippines } & 1993 & 20.6 & 36.3 & 56.2 & 70.5 & 78.7 & 52.5 & 3.81 \\
\hline & 1998 & 6.7 & 12.7 & 23.8 & 40.0 & 49.9 & 26.6 & 7.50 \\
\hline & 2003 & 19.6 & 42.2 & 61.2 & 75.2 & 82.9 & 56.2 & 4.23 \\
\hline \multirow{3}{*}{ Rwanda } & 1992 & 1.0 & 0.2 & 1.3 & 1.7 & 4.8 & 1.8 & 4.77 \\
\hline & 2000 & 0.3 & 0.2 & 0.4 & 0.9 & 6.0 & 1.6 & 18.48 \\
\hline & 2005 & 0.4 & 0.6 & 1.0 & 1.2 & 8.0 & 2.2 & 21.13 \\
\hline \multirow{2}{*}{ Senegal } & 1992 & 0.7 & 1.9 & 2.1 & 2.8 & 8.8 & 3.2 & 12.81 \\
\hline & 2005 & 0.9 & 0.9 & 1.1 & 3.7 & 5.5 & 2.4 & 6.04 \\
\hline & 1992 & 0.0 & 0.2 & 0.3 & 0.1 & 0.7 & 0.3 & n.d. \\
\hline Tanzania & 1996 & 0.3 & 0.6 & 0.6 & 0.4 & 1.7 & 0.7 & 6.11 \\
\hline & 2004 & 0.2 & 0.2 & 0.1 & 0.4 & 3.1 & 0.8 & 15.06 \\
\hline & 1995 & 2.3 & 3.6 & 4.4 & 10.1 & 27.4 & 9.6 & 11.73 \\
\hline Uganda & 2000 & 0.6 & 1.8 & 3.2 & 5.4 & 15.1 & 5.2 & 24.05 \\
\hline & 2006 & 1.6 & 2.7 & 2.7 & 3.9 & 14.9 & 5.1 & 9.44 \\
\hline & 1997 & 1.5 & 6.4 & 11.5 & 23.4 & 42.9 & 17.1 & 27.79 \\
\hline Vietnam & 2002 & 3.2 & 13.2 & 18.4 & 33 & 50.8 & 23.7 & 15.96 \\
\hline & 1992 & 0.7 & 0.9 & 2.9 & 5.3 & 15.3 & 5.0 & 20.49 \\
\hline Zambia & 1996 & 0.2 & 0.3 & 0.0 & 0.6 & 2.3 & 0.7 & 9.62 \\
\hline & 2001 & 0.3 & 1.6 & 3.5 & 5.1 & 21.3 & 6.3 & 83.00 \\
\hline & 1994 & 0.0 & 0.5 & 1.0 & 1.4 & 4.3 & 1.4 & n.d. \\
\hline Zimbabwe & 1999 & 12.4 & 18.6 & 26 & 38.3 & 63.7 & 31.8 & 5.15 \\
\hline & 2006 & 0.5 & 1.3 & 2.0 & 4.5 & 14.9 & 4.6 & 30.54 \\
\hline
\end{tabular}

Source: Demographic and Health Surveys; own calculations. 